\title{
Karl Borchardt
}

\section{Illegitime in den Diözesen Würzburg, Bamberg und Eichstätt}

Aus den drei fränkischen Diözesen Würzburg, Bamberg und Eichstätt erscheinen in den Registern der päpstlichen Pönitentiarie von 1447 bis 1534 insgesamt 561 Dispense super defectu natalium, aus Würzburg 340, aus Bamberg 93 und aus Eichstätt 128.' Man vergleiche dazu Straßburg mit 205 Personen (Francis Rapp im vorliegenden Band). Die Zahl der betroffenen Personen liegt aus zwei Gründen etwas niedriger. Zum einen steht dieselbe Person zweimal bei erster oder einfacher und später bei erweiterter Dispens. Zum anderen wird dieselbe Dispens wiederholt, wenn sich nachträglich Angaben zu Eltern, früherer Verschweigung, Weihegrad oder Namen als falsch herausstellten oder andere Kommissare gewünscht wurden. Insgesamt treten, soweit sich das erkennen läßt, $522 \mathrm{Per}-$ sonen auf. Bezeichnet wird der Petent entweder schon als Kleriker - manchmal genauer Akolyth oder bereits Priester - oder doch als Scholar und damit potentiell angehender Kleriker.

Unter den Petenten befinden sich nur sechs Frauen, die alle in ihren Orden Ämter erwerben wollten: Barbara Baeviere Eichstätter Diözese 1478 Januar erste Dispens religiosus ordinis eremitarum sancti Augustini et soluta (Reg. Pen. $26224 \mathrm{v}-\mathrm{DN}$-Antragsnr. 13342); die Zisterzienserin in Seligenporten Herzogin Katharina von Bayern 1498 April erste Dispens solutus et soluta (Reg. Pen. 46 429v - DN-Antragsnr. 23151); Ursula, Anna und Cecilia, Töchter des [Niederadeligen] Johann Nothaft Würzburger Diözese, 1499 Dezember erste Dispens miles et monialis (Reg. Pen. 48 829r - DN-Antragsnr. 2414850); Barbara Ammon Würzburger Diözese 1501 Juli erste Dispens presbiter et soluta gemeinsam mit ihren Brüdern Jodokus und Nikolaus (Reg. Pen. $49724 \mathrm{v}-$ DNAntragsnr. 25390-92). Da der Eintritt ins Kloster nach D. 56 c. 2 und der zugehörigen Glosse grundsätzlich ohne Dispens möglich war, brauchten Religiosen nur um Dispens einzukommen, wenn sie Ämter in ihren Orden erstrebten. Genannt werden zwei Männer, Donatus Odenwan Benediktiner Eichstätter Diözese, Propst des Schottenklosters Heilig-

I Ludwig Schmugge und seinen Mitarbeitern sei herzlich dafür gedankt, daß sie ihre Funde großzügig zur Verfügung stellten, ebenso für zahlreiche Hinweise den Teilnehmern des Kolloquiums in München, auf dem im April 1992 eine erste Fassung der folgenden Ausfiuhrungen vorgetragen wurde. Zu danken ist ferner dem Diözesanarchiv Würzburg für die Benutzung der Kartei Weiß-Wissen, die in der Sekundärliteratur genannte Geistliche der Diözese verzettelt, und den Bearbeitern von RG 9, den Herren Hubert Höing, Heiko Leerhoff und Michael Reimann, alle Hannover, für die Einsicht in ihr Manuskript [mit provisorischer Numerierung]. 
kreuz zu Eichstätt, 1455 November einfache Dispens solutus et soluta zum Erwerb der Abtswürde (Reg. Pen. 6 56r - DN-Antragsnr. 302), und Johann Favemberger Scholar Bamberger Diözese 1473 April einfache Dispens presbiter et soluta (Reg. Pen. 21 179r DN-Antragsnr. 37220). Damit bleiben 514 Weltgeistliche, doch erfaßt diese Zahl aus mehreren Gründen nicht alle illegitimen Kleriker der drei Diözesen:

Zum einen sind nur 86 Pönitentiarie-Register erhalten. Mindestens zwölf Bände fehlen, je ein Band Nikolaus V., Pius II., Paul II. und Alexander VI. , zwei Bände Leo X. und je drei Bände Julius II. und Clemens VII. ${ }^{2}$ Die Verluste lassen sich nicht genau abschätzen, da die Pönitentiarie ebenso wie die Kanzlei verschiedene Registerserien führte und erhaltene Bände mitunter unvollständig sind (Filippo Tamburini im vorliegenden Band). Die Zahl der fränkischen Petenten ging anscheinend nach 1520 drastisch zurück, wahrscheinlich aufgrund der Reformation.

Zum zweiten tauchen nicht alle, die sich vom Papst per fiat oder vom Vizekanzler bzw. referendarius domesticus per concessum Dispens erteilen ließen, in der Pönitentiarie auf. Unter Sixtus IV., dessen Pönitentiarie-Register wohl vollständig erhalten sind, bekam Johann Rotteling Kleriker Würzburger Diözese am 8. Juni 1472 Dispens presbiter et soluta ${ }^{3}$, ist aber mit Johann Rowt Scholar Würzburger Diözese 1472 August einfache Dispens solutus et soluta (Reg. Pen. 21 168v - DN-Antragsnr. 10158) nicht identisch. Johann Rotteling könnte natürlich ohne Angabe der Diözese oder mit zerschriebenem Namen auftreten; obwohl man den Einzelfall nicht pressen darf, bleibt festzuhalten, daß die Register der Pönitentiarie, selbst wenn sie vollständig überliefert wären, keineswegs alle Personen aufführen, die sich an der römischen Kurie um Dispens super defectu natalium bemühten. ${ }^{4}$

Zum dritten erteilten Dispense nicht nur Papst, Vizekanzler, referendarius domesticus und Großpönitentiar, sondern auch auctoritate apostolica päpstliche Legaten und Nuntien auf Reisen oder ständige Delegierte in partibus. Kardinäle wie Nikolaus von Kues und Juan Carvajal oder als legatus de latere der unten (vgl. Tierberg) genannte Bischof Bartholomäus von Città di Castello erhielten gewöhnlich die Fakultät, zehn oder 30 oder eine andere feste Zahl solcher Dispense wie auch Legitimationen vorzunehmen. ${ }^{5}$ Auf drei Fälle wird in den Pönitentiarie-Registern ausdrücklich verwiesen: durch den Kardinal von Sant'Angelo Juan Carvajal Johann Prungher Kleriker Eichstätter Diözese 1457 Oktober

2 Diese Zahlen nach Emil Göller, Das alte Archiv der päpstlichen Pönitentiarie, in: RQA Supplementheft 20 (1913) $5 f$.

3 Wilhelm Engel (Hrsg.), Vatikanische Quellen zur Geschichte des Bistums Würzburg im 14. und 15. Jahrhundert (Quellen und Forsch. zur Gesch. des Hochstifts und der Diözese Würzburg [künftig: QFW] 1, Würzburg 1948) 219 Nr. 1408, im folgenden zitiert: Engel, Quellen; Theodor Joseph Scherg Franconica aus dem Vatikan 1464-1487 [/1492], in: Arch. Zs. 17 (1910) 241 Nr. 389 nach ASV L 722 23r. Im folgenden zitiert: Scherg, Franconica.

4 Anscheinend nicht in den Registern der Pönitentiarie: Martin Lucher Ewigvikar am Marienaltar der Stiftskirche St. Cecilia zu Rasdorf Diözese Würzburg mit Dispens solutus et soluta 1487 Oktober 23 Erlaubnis, sich an der römischen Kurie zum Priester weihen zu lassen: ASV S 878, 153r; Johann Calopaficis [?] Würzburger Diözese, päpstlicher Familiar mit Dispens monachus ordinis sancti Benedicti et soluta 1491 September 2 Pfarrkirche Gotterß (Gotthards?) Diözese Würzburg 8 Kammergulden nach Tod des Heinrich NN: ASV S 942, 167r.

5 Z.B. Juan Carvajal 1455 September 17: ASV V 442 105rv; RG 7150 Nr. 1338. 
erweiterte Dispens presbiter et soluta (Reg. Pen. 6401 r - DN-Antragsnr. 1774); durch den Kardinal Francesco Todeschini-Piccolomini Johann Henneberger Kleriker Würzburger Diözese 1485 Januar erweiterte Dispens clericus et monialis (Reg. Pen. 34 252v - DNAntragsnr. 16337); durch ungenannten Legaten Bartholomäus Som [?] Subdiakon Würzburger Diözese 1533 April erweiterte Dispens presbiter et soluta für zwei Pfründen, da er schon ein beneficium simplex besaß (Reg. Pen. 82 20r - DN-Antragsnr. 33088). ${ }^{6}$ Mit der Dispens auctoritate apostolica konkurrierten im 15. Jahrhundert die Konzilien: durch das Konzil von Basel Johann Fariant Priester Würzburger Diözese 1454 Mai erweiterte Dispens presbiter et soluta per fiat (Reg. Pen. $4151 \mathrm{v}$ - DN-Antragsnr. 37220). Wenn der Papst seine Dispensgewalt an den Großpönitentiar, an Legaten oder Ordensvorsteher delegierte, waren davon gewöhnlich Söhne von Priestern und Ordensangehörigen sowie Fälle von Ehebruch und Inzest ausgenommen.

Viertens konnte auctoritate ordinaria der Ortsbischof vom defectus natalium dispensieren, freilich nach dem Liber Sextus 1.11.1 und 1.11.2 nur für niedere Weihen und einfache Pfründen. Auf neun derartige Fälle wird als Vordispens verwiesen: Jakob Eich 1452, Thomas von Neuhaus 1454, Johann von Romrod 1455, Sigisimund Zweifel 1465, Georg Plachseiber 1492, Erasmus Volmar 1495, Johann Lamerpach 1500. Notare waren im 15. Jahrhundert in Franken fast immer Kleriker und zeichneten öfters ausdrücklich als clericus coniugatus. $^{7} \mathrm{Ob}$ und welche Dispens ihre Kinder benötigten, wäre zu untersuchen. Ein Beispiel könnten die Sternhals in Bamberg liefern: Michael Sternhals 1421-1426 Domvikar Bamberg; Erasmus Sternhals, der 1427 für den Domkanoniker zu Bamberg, Graf Georg von Löwenstein, einen Heilsspiegel mit prächtigen Miniaturen schrieb, in Bamberg Notar 1430-1448, Domvikar, Stiftskanoniker St. Stephan, Mitglied der Bruderschaft bei den Karmeliten, 1437 Schreiber des Domkantors Georg von Schaumberg; Johann Sternhals Kleriker Bamberger Diözese 1465 März erweiterte Dispens diaconus et soluta per fiat, besaß eine Pfründe ohne Seelsorge (Reg. Pen. 12 162r, 168r - DN-Antragsnr. 5476, 5501), anwesend an der römischen Kurie 1465 Mai 16 Ewigvikar in St. Jakob außerhalb Bamberg 3 Mark Erlaubnis zum Empfang der Weihen außerhalb der vorgeschriebenen Zeiten, 1466 Dezember 28 dispensatio uberior, 1471/77 Notar und Domvikar in Bamberg. ${ }^{8}$

6 Vgl. Georg Sonn oder Som aus Ochsenfurt, Zisterzienser in Ebrach, 1489 Studium Heidelberg, Doktor der Theologie, gestorben 1520 April 20: Johannes Kist, Ebracher Zisterzienser und ihr Universitätsstudium im Mitrelalter, in: Würzburger Diözesangeschichtsbll. 14/15 (1952/53) 346; Johann Jaeger, Verzeichnis der Äbre und Religiosen der Cistercienser-Abtei Ebrach 1126-1803, in: Cistercienser-Chronik 14 (Bregenz 1903) 47.

7 Z.B. Andreas Eischinger in der Stadt Würzburg, 1491 Februar 27: ASV S $932118 \mathrm{v}-119 \mathrm{r}$.

8 Friedrich Wachter, General-Personal-Schematismus der Erzdiözese Bamberg 1007-1907 (Bamberg 1908) 489f. Nr. 9885-9887 mit Michael Sternhals, der 1424 durch Markgraf Johann vergeblich auf eine Domvikarie zu Bamberg präsentiert wurde; im folgenden zitiert: Wachter, Schematismus. Jobannes Kist, Die Matrikel der Geistlichkeit des Bistums Bamberg 1400-1556 (Veröffentlichungen der Ges. für fränkische Gesch. IV/7, Würzburg 1965) 399f. Nr. 6087-6089; im folgenden zitiert: Kist, Matrikel; RG 9 Nr. 4040; Klaus Frbr. v. Andrian-Werburg, Ein Bruderschaftsverzeichnis der Bamberger Karmeliten, in: Würzburger Diözesangeschichtsbll. 42 (1980) 204; Hans Thurn, Die Handschriften des 15. Jahrhunderts aus der Benediktinerabtei St. Stephan zu Würzburg, in: Würzburger Diözesangeschichtsbll. 47 (1985) 64. 
Schließlich konnten grundsätzlich Legitimationen auctoritate regia vel imperiali vorgenommen werden. Ludwig der Bayer erlaubte 1327 seinem Vertrauten Graf Berthold VII. von Henneberg 20 und jedem von dessen Nachfolgern als Besitzer der Burg Henneberg zehn Legitimationen, aber ausdrücklich nur für zivile Ämter und Rechtsakte ad succedendum parentibus, obtinendum honores civiles, et quoslibet actus legitimos exercendum? Gewöhnlich verband sich damit die Erlaubnis zur Kreation von Notaren, hier für Berthold zehn und für jeden seiner Nachfolger sechs. Entsprechende Vollmachten konnten geistliche Fürsten erhalten, beispielsweise 1353 Erzbischof Wilhelm von Köln für 100 Notare und 100 Legitimationen. ${ }^{10}$ Die Quellenlage für solche Akte auctoritate regia vel imperiali ist schlecht, zumal aus dem 15. Jahrhundert keine Hofpfalzgrafenregister vorliegen und die Reichsregister daraufhin noch nicht ausgewertet wurden. Allerdings sind weltliche Legitimation und kirchliche Dispens zu trennen. Natürlich konnte auch der Papst legitimieren. So beauftragte 1465 Paul II. den Bischof von Würzburg, dem Johann Hermann und der Margarethe Franck von Flyn, Laien Würzburger Diözese, die mehrfach miteinander fleischlich verkehrt und Kinder gezeugt hatten, obwohl Margarethes Vater Johanns Taufpate war, nach Auferlegung einer Buße Dispens zu erteilen, damit sie heiraten können, und ihre Kinder zu legitimieren. Alexander VI. beauftragte 1495 den Bischof von Würzburg, dem Michael Herbst und der Dorothea Niesmann Würzburger Diözese, die geheiratet hatten, ohne zu wissen, daß sie im zweiten Grade verwandt waren, weil nämlich der erste Gatte der Dorothea mit Michael im zweiten Grade verwandt war, Dispens zu erteilen und etwaige Kinder zu legitimieren. ${ }^{11}$ Wer Geistlicher werden wollte, wird sich aber in der Regel nicht um Legitimation, sondern um Dispens bemüht haben.

Die genannten Faktoren in Rechnung gestellt, möchte ich angesichts der 514 Personen in den Pönitentiarie-Registern die Gesamtzahl der Illegitimen bei fränkischen Klerikern mit allem Vorbehalt auf kaum höher als 1000 schätzen. Die größte Unsicherheit entsteht dabei durch die Dispense auctoritate ordinaria, für die praktisch keine Quellen vorliegen. Will man nun den Anteil der Illegitimen am fränkischen Klerus dieser Jahre überschlagen, begibt man sich noch stärker auf schwankenden Boden. Weihematrikeln sind nur ausnahmsweise erhalten. Ausgehen kann man also nur von der Zahl der Pfründen. Eichstätt hatte nach der Diözesanmatrikel von 1480 und ergänzenden Untersuchungen von Joseph Georg Suttner damals 790 Geistliche: 97 Kanoniker, 46 Vikare, 307 Pfarrer, 251 Meßpfründner und 89 cooperatores (Mietlinge) ${ }^{12}$; durch Neustiftungen stiegen diese Zahlen bis zum Beginn der Reformation. Bamberg hatte nach einer Steuerliste von 1421

9 Trient 1327 März 15: Hennebergisches Urkundenbuch, Teil 1. Hrsg. v. Karl Schöppach (Meiningen 1842) $107 f$. Nr. 191.

10 Karl IV., Mainz 1353 Dezember 18, Urkundenbuch des Niederrheins. Hrsg. v. Theodor Joseph Lacomblet, Bd. 3 (1840/1858, ND Aalen 1960) 430 Nr. 527: cum centum personis patientibus defectum natalium quoad successiones, honores et dignitates et munerum publicorum functiones, et ad quoscumque actus legitimos eadem nostra auctoritate regia dispensare, ipsosque restituere valeas ea integritate, ac si fuissent de thoro legitimo procreati, dummodo ista fiant absque beredum legitimorum dispendio et iactura.

11 1465 März 11: ASV L 642 119r; Zahlung von 8 Kammergulden für diese Dispens 1466 März 26: ASV IE 465 17r, IE 466 18r; RG 9 Nr. 3348; 1495 Oktober 31: ASV V 881 39rv.

12 Joseph Georg Suttner, Schematismus der Geistlichkeit des Bisthums Eichstätt für das Jahr 1480. Programm des bischöflichen Lyceums in Eichstätt (Eichstätt 1879) 92; im folgenden zitiert: Suttner, Schematismus. 
damals 447 Geistliche, nach Berechnungen von Heinrich Weber am Vorabend der Reformation 604 Benefizien: 56 Kanonikate, 12 Domizellare, 185 Pfarreien, 351 Frühmessen, Kaplaneien und sonstige Pfründen ${ }^{13}$; dabei fehlen allerdings die nicht fest bepfründeten Mietlinge. Würzburg hatte nach einer Diözesanmatrikel aus der Mitte des 15. Jahrhunderts 849 Pfarreien und 652 einfache Meßpfründen, allerdings ohne die über 100 Pfründen in der Stadt Würzburg selbst und ohne die Vikarien der Kollegiatstifte, von denen Neumünster allein 32 besaß. ${ }^{14}$ Das ergibt insgesamt über 1600 Pfründen, eine Zahl, die bis zur Reformation nach meiner Schätzung auf knapp 2000 stieg. Wenn man überschlagsmäßig für die Jahre 1447 bis 1534 in Würzburg mit durchschnittlich 1800 , in Bamberg mit durchschnittlich 600 und in Eichstätt mit durchschnittlich 800 Pfründen rechnet, also 3200 Pfründen insgesamt, müßten während dreier Generationen über 10000 Geistliche dort bepfründet gewesen sein. Das ergäbe bei 514 oder geschätzten 1000 Illegitimen einen Anteil von fünf bis höchstens zehn Prozent.

In Wirklichkeit lag dieser Anteil wahrscheinlich niedriger, denn trotz Pfründenkumulation muß man eher mit mehr Geistlichen und weniger Illegitimen rechnen. Selbstverständlich wurden Benefizien in den Diözesen Würzburg, Bamberg und Eichstätt nicht selten an Kleriker anderer Diözesen verliehen, wie umgekehrt Kleriker aus Würzburg, Bamberg oder Eichstätt anderwärts bepfründet waren. Gerade Illegitime lebten öfters weit entfernt von ihrer Heimat: Benedikt Prenninger von Ingolstadt Scholar Eichstätter Diözese 1492 April erste Dispens solutus et soluta mit Kommission an den Bischof von Konstanz, weil er dort lebte (Reg. Pen. $41344 \mathrm{r}-$ DN-Antragsnr. 20733). ${ }^{15}$ Erasmus Schütz Scholar Würzburger Diözese 1470 Mai erste Dispens presbiter et soluta (Reg. Pen. 18 246r - DN-Antragsnr. 8670), Kleriker ohne Pfründe, 1470 Juni 15 Pfarrkirche St. Andreas Vster [?] Konstanzer Diözese 5 Mark; unter Dispens presbiter et coniugata [!] 1476 Altar St. Thekla im Dom zu Konstanz 4 Mark. ${ }^{16}$ Johann Zimmermann Würzburger Diözese Scholar 1490 Juni erste, Kleriker 1495 Juni erweiterte Dispens presbiter et soluta per fiat, besaß 1495 Vikarie St. Katherina in der Kirche St. Silvester in der Stadt

13 Georg Kanzler, Die Landkapitel im Bistum Bamberg, in: Ber. des HV vom Bamberg 83 (1931) 32f.; Heinrich Weber, Das Bisthum und Erzbisthum Bamberg, seine Einteilung in alter und neuer Zeit und seine Patronatsverhältnisse, in: Ber. des HV vom Bamberg 56 (1895) 151 mit Anm. 5. Nur 164 Pfarreien nennt Erich Frhr. von Guttenberg, Alfred Wendehorst, Das Bistum Bamberg, Teil 2: Die Pfarreiorganisation (Germania Sacra 2/1, Berlin 1966) 32; im folgenden ziriert: von Guttenberg, Wendehorst, Bamberg.

14 Franz Joseph Bendeh, Die Würzburger Diözesanmatrikel aus der Mitte des 15. Jahrhunderts, in: Würzburger Diözesangeschichtsbll. 2 (1934) XVIIf., XXVII, im folgenden zitiert: Bendeh Diözesanmatrikel; Alfred Wendehorst, Das Stift Neumünster in Würzburg (Germania Sacra NF. 26, Berlin/New York 1989) $149 f$; im folgenden zitiert: Wendehorst, Neumünster.

15 Dr. Martin Uranius Brenninger Professor in Tübingen, sein Sohn Dr. Marsilius Brenninger geboren um 1480/85, seir 1525 fürstbischöflicher Kanzler zu Würzburg, dessen Bruder Bernhard 1527 Domvikar, dazu weitere Verwandte: Theobald Freudenberger, Das Ringen um das Würzburger Reformstatut über das Lebensalter der Bewerber um Domvikarpfründen, in: Würzburger Diözesangeschichtsbll. 26 (1964) 208215: Ludwig Weiß, Pfründenverleihungen im Nordosten des Bistums Würzburg in der ersten Hälfte des 16. Jahrhunderts, in: Würzburger Diözesangeschichtsbll. 26 (1964), 241; im folgenden zitiert: Weiß, Nordosten.

16 RG 9 Nr. 1219; Scherg, Franconica (wie Anm. 3), 2 274, Nr. 507; Engeh, Quellen (wie Anm. 3), 228 Nr. 1481. Vgl. Ludwig Schütz Scholar Würzburger Diözese 1463 November einfache Dispens presbiter et soluta (Reg. Pen. 11 345v - DN-Antragsnr. 4454). 
Wernigerode Diözese Halberstadt (Reg. Pen. 39 414v, 44 397v - DN-Antragsnr. 19732, 22465). ${ }^{17}$ Georg von Nürnberg Scholar Bamberger Diözese 1501 November erste Dispens de illicito coitu procreatus mit Kommission an Dompropst zu Dorpat wegen der räumlichen Entfernung (Reg. Pen. 50 334r - DN-Antragsnr. 25637).

So aufschlußreich Kommissionen sein können ${ }^{18}$, Johann Neumeier erhielt als Scholar Eichstätter Diözese 1516 Mai erste Dispens solutus et soluta mit Kommission an den Dompropst zu Meißen (Reg. Pen. 60 358r - DN-Antragsnr. 29356) vermutlich deshalb, weil er in Leipzig studierte. ${ }^{19}$ An der römischen Kurie lebte Johann Jacobi Scholar Würzburger Diözese 1450 April einfache Dispens presbiter et soluta (Reg. Pen. $434 \mathrm{v}-$ DN-Antragsnr. 34388); Familiar des Kardinals Theodor von Montferrat [Kardinaldiakon von St. Theodor 1467-1484, zuvor apostolischer Protonotar], 1481 Pfarrer Gochsheim 9 Mark, angeblich an der römischen Kurie verstorben vor 1484 September 22, aber genannt 1485 März 22 als Pfarrer Baunach Diözese Würzburg 10 Mark. ${ }^{20}$ Genauere Zahlen über den Klerus lassen sich beim jetzigen Stand der Forschung nicht geben. Selbst wenn der Anteil der Illegitimen fünf oder, was durchaus möglich ist, nur drei Prozent betrug, überrascht die hohe Zahl nachgewiesener Einzelfälle angesichts der seit dem Hochmittelalter eindeutigen und strengen kirchlichen Gesetzgebung. ${ }^{21}$

Eine Erklärung liefert das Zusammenleben der Geistlichen mit Haushälterinnen. Etwa drei Fünftel aller Dispense, fast 300, wurden nämlich de presbitero et soluta erteilt; dazu kommen noch knapp 30 sonstige Geistliche mit einer soluta. Dem stehen gegenüber nicht ganz 200 Dispense, wo der Vater solutus war und die Mutter soluta. Ehebruch von Geistlichen mit coniugate unter Mißbrauch seelsorgerlicher Beziehungen ist mit knapp 40 Fällen im Gegensatz zu einem im Spätmittelalter verbreiteten literarischen Topos in der Wirklichkeit offenbar eher selten. Weit über die Hälfte der illegitimen Geistlichen waren also selbst Kinder von Geistlichen. Wieviele der Kinder von Geistlichen ihrerseits wieder Geistliche wurden, läßt sich beim besten Willen nicht abschätzen. Es gibt Beispiele von solchen Illegitimen, die anscheinend Laien blieben, in Rothenburg etwa Konrad, Sohn des Dorfpfarrers Stephan Talheim. ${ }^{22}$ Systematisch danach zu suchen, ist schwer. Andererseits

17 Ein Johann Zimmermann 1526 Vikar Sternberg im Grabfeld: Franz Georg Benkert, Das ehemalige Landcapitel Mellerichstadt beim Beginne der s. g. Reformation und kurz nach dem Bauernkriege, in: Arch. des HV von Unterfranken 12/2-3 (1853) 116; im folgenden zitiert: Benkert, Landcapitel; Franz Joseph Bendeh Visitationsbericht über das Kapitel Mellrichstadt, in: Würzburger Diözesangeschichtsbll. 6 (1938) 43; im folgenden zitiert: Bendel, Visitationsbericht.

18 Bemerkenswert der päpstliche Zeremonienmeister Johannes Burcardus als Bischof von Orte Kommissar bei einfacher Dispens solutus et soluta 1504 Mai für Jakob Wirsberger Scholar Bamberger Diözese (Reg. Pen. 52 644v - DN-Antragsnr. 26295).

19 Freilich wird er nicht genannt bei Georg Erler (Hrsg.), Die Matrikel der Universität Leipzig, nach dem Index Bd. 3 (Leipzig 1901) 596.

20 Scherg, Franconica (wie Anm. 3), 3 128, Nr. 808; 156 Nr. 905; 1485 März 22: S 850 193r; Bendeh Diözesanmatrikel (wie Anm. 14), 4 Nr. 116; Eubel, Hierarchia catholica medii aevi, Bd. 2 (Münster 1914) 67.

21 Schimmelpfennig, Zölibat; Sprandeh Diskriminierung.

22 Karl Borchardt, Die geistlichen Institutionen in der Reichsstadt Rothenburg ob der Tauber und dem zugehörigen Landgebiet von den Anfängen bis zur Reformation (Veröffentlichungen der Ges. für fränkische Gesch. 9/37, Neustadt/Aisch 1988) 576f. Nr. 196; im folgenden zitiert: Borchardt, Rothenburg. 
lag es analog zu Handwerkern und Bauern nahe, daß Söhne den Beruf ihres Vaters ergriffen.

Durch diskriminierende Zunftbestimmungen gegen Illegitime, für die es freilich aus dem 15. Jahrhundert keine fränkischen Beispiele gibt (Knut Schulz im vorliegenden Band), mag diese Tendenz verstärkt, wenn auch nicht verursacht worden sein. Es gab regelrechte Priesterdynastien: Kaspar Stoll Scholar Würzburger Diözese 1451 November erste Dispens coniugatus et soluta (Reg. Pen. $657 \mathrm{v}$ - DN-Antragsnr. 35985). Melchior Stoll Scholar Würzburger Diözese 1483 April erste Dispens presbiter et soluta (Reg. Pen. 32 205r - DN-Antragsnr. 15740); 1482 Studium Leipzig, Kaplan Krailshausen 1495 und zusärzlich Dunzendorf 1500, Pfarrer Schmalfelden 1509, als sein Sohn Sebastian gegen Wendel Ferg in Rothenburg klagte, weil dieser Sebastians Sohn Schuld am Verlust einiger Wertsachen gab, Pfarrer Michelbach an der Lücke 1513 bis 1545 [Präsentation durch Stift Neumünster], 1519 Erste Bitten Karls V. auf Dominikanerinnenkloster Rothenburg. Sebastian Stoll Scholar Würzburger Diözese 1517 September erste Dispens presbiter et soluta (Reg. Pen. 61 396v - DN-Antragsnr. 30105); 1525 Geistlicher in Rorhenburg, als er an Peter Glaser Lehrgeld zahlen sollte, vermutlich weil er während der Unruhen den geistlichen Stand verlassen hatte, 1531 Pfarrer Gammesfeld [Präsentation Stadt Rothenburg]..$^{23}$ Solche Familientradition setzte sich normalerweise vom Onkel auf den Neffen fort, aber gar nicht so selten auch über eigene Kinder. Darauf deuten mehrfach Namen von Brunner über Caroli, Klüpfel, Fleischmann, Lemlein, Nibling, Senft, Spet, Steinmetz, Widmann bis Zehringer in den Pönitentiarie-Registern hin. Wenn wirklich der Pfarrer Lorenz Reichlin um 1500 sich mit Frau und Kindern im Chor seiner Kirche malen ließ so jedenfalls interpretiert Gerhard Wunder die 1955 in Michelbach an der Bilz unweit Schwäbisch Hall, Diözese Würzburg, entdeckten Fresken ${ }^{24}$-, bestätigt das Verhältnisse, die mit der Reformation für protestantische Pfarrerfamilien legalisiert wurden.

Ausschlaggebend für die Entstehung von Priesterdynastien schon vor der Reformation war zum einen der Wunsch, stets wenigstens einen Fürbitter in der eigenen Familie zu haben $^{25}$, zum anderen die Möglichkeit, vom Onkel oder - seltener - eben vom eigenen Vater kostengünstig ausgebildet und durch dessen Beziehungen gefördert zu werden. Wegen der Gefahr, daß Kirchengut zu Familienbesitz entfremdet wurde, nahm das kanonische Recht zwar entschieden gegen solche Verhältnisse Stellung, konnte sie aber nicht verhindern. In zwei Fällen wird Dispens ausdrücklich erteilt, damit der Sohn am gleichen Ort wie der Vater - ubi pater - eine Pfründe erwerben kann: Heinrich Ludovici Würzburger Diözese Scholar 1476 Mai und 1477 Februar erste, Kleriker 1480 Oktober erweiterte Dispens presbiter et soluta per fiat für ein Kanonikat ohne Seelsorge (Reg. Pen. 24 217r, 25 175r, 30 126r, 141v - DN-Antragsnr. 12607, 12902, 14490, 14832), 1480 Vikar in Hünfeld ${ }^{26}$; Emmeram Hahndorffer Kleriker Eichstätter Diözese 1486 August

24 Gerhard Wunder, Die Bürgerschaft der Reichsstadt Hall von 1395 bis 1600 (Württembergische Geschichtsquellen 25, Stuttgart/Köln 1956) 71 f.

25 So begründeten drei Franziskaner 1525 ihren Wunsch, aus dem Orden auszutreten: Borchardt. Rothenburg (wie Anm. 22), 212 mit Anm. 18.

${ }^{26}$ Engel, Quellen (wie Anm. 3), 249f. Nr. 1631. Vgl. Engelhard Ludovici Scholar Würzburger Diözese 1470 Juni einfache Dispens presbiter et soluta (Reg. Pen. 18 249r - DN-Antragsnr. 8744). 
erweiterte Dispens presbiter et coniugata (Reg. Pen. 35 214v - DN-Antragsnr. 16989). Auf Kilian Reuß, Kleriker Würzburger Diözese, Pfarrer Berkach 3 Mark Silber, der 1488 zunächst Aufschub der Priesterweihe und dann die Erlaubnis zur Priesterweihe an der römischen Kurie erbat, folgte offenbar der eigene Sohn in der Pfarrei: Kilian Reuß (Reusch) Scholar Würzburger Diözese 1516 Juli erste Dispens presbiter et soluta (Reg. Pen. 60 366v - DN-Antragsnr. 29444); 1518 bis zu seinem Tod vor 1530 April 23 Pfarrer Berkach bei Mellrichstadt [Präsentation gemäß Turnus durch Domkanoniker zu Würzburg]. ${ }^{27}$ Graf Johann von Henneberg-Schleusingen brachte seinen murmaßlichen Sprößling auf der Schloßkapelle Mainberg unter: Johann Henneberger Kleriker Würzburger Diözese 1485 Januar erweiterte Dispens clericus et monialis, während zuvor durch Kardinal Francesco Todeschini-Piccolomini dispensiert (Reg. Pen. 34 252v - DNAntragsnr. 16337); zwischen 1490 und 1500 Kaplan der Burg Mainberg [Präsentation Graf von Henneberg-Schleusingen]. Graf Johann von Henneberg-Schleusingen, geboren 1439 Juli 2, Domkanoniker zu Würzburg, dann Benediktiner, Propst der Benediktinerinnen [!] von Thulba, seit $1472 \mathrm{Abt}$ von Fulda, gestorben $1513 \mathrm{Mai} 20{ }^{28}$

Ein drastisches Beispiel liefert Johann Herdigen aus Kitzingen, Scholar Würzburger Diözese 1458 Juni einfache Dispens presbiter et soluta (Reg. Pen. 6 133r - DN-Antragsnr. 1538); als er 21 Jahre alt war, verlieh ihm sein Vater, der Priester Würzburger Diözese Friedrich Beyer alias Wahrsager, nach dem Tod des Stephan Haug 1463 die Mittelmesse am Marienaltar der Pfarrkirche Niedernbreit, die von seiner Familie gestiftet worden war (de iure patronatus laicorum) und deren Patronatsrecht Friedrich geerbt hatte. Bischof Gottfried von Würzburg hatte 1447 die Mittelmesse bestätigt, und zwar mit Zustimmung durch den damaligen Pfarrer Friedrich Beyer genannt Wahrsager, den Neffen der Stifterin Gertrud Pfister; das Präsentationsrecht erhielt Pfarrer Friedrich auf Lebenszeit, danach die Gemeinde, welche jedoch wenn möglich ein Mitglied der Familie Beyer präsentieren sollte. Um die Meßpfründe rechtmäßig anzutreten, brauchte Johann Herdigen 1464 zusätzlich Dispens super defectu oculi sinistri; ferner erhielt er 1465 Exspektativen auf Stift Haug und das Benediktinerinnenkloster Kitzingen; er studierte 1458 in Heidelberg, 1471 in Erfurt (?, dort von Aub genannt), war Kaplan im Spital zu Kitzingen, wurde 1485 Spitalpfarrer zu Kitzingen und starb vor 1500. Sein Vater Friedrich Beyer genannt Wahr-

271488 Januar 29: ASV S 881 260rv; 1488 April 15: ASV S 884 56v; Benkert, Landcapitel (wie Anm. 17), 111; Ludwig Remling, Bruderschaften in Franken. Kirchen- und sozialgeschichtliche Untersuchungen zum spätmittelalterlichen und frühneuzeitlichen Bruderschaftswesen (QFG [wie Anm. 3] 35, Würzburg 1986) 204 Anm.; im folgenden zitiert: Remling, Bruderschaften; Bendeh Visitationsbericht (wie Anm. 17), 41; Weiss, Nordosten (wie Anm. 15), 230f.

${ }^{28}$ Joachim Ablbom, Die Schloßkapelle Mainberg zu Zeiten der Grafen von Henneberg-Schleusingen, in: Würzburger Diözesangeschichrsbll. 43 (1981) 402, 407, 411; Engeh, Quellen (wie Anm. 3), 217 Nr. 1399; 218 Nr. 1402; Dominikus Heller, Wilhelm Engeh Beiträge zur Kirchengeschichte des Bezirkes Hammelburg, in: Würzburger Diözesangeschichtsbll. 13 (1951) 165; nicht zu verwechseln mit seinem Großneffen Johann, geboren 1503 April 30, Propst von Holzkirchen, Koadjutor von Fulda 1521, gestorben 1541 Mai 20: August Amrhein, Geschichre des ehemaligen Benediktinerklosters Holzkirchen, in: Arch. des HV von Unterfranken 38 (1896) 91; Frank Baron Freytag v. Loringhoven, Europäische Stammtafeln, Bd. 3 (Marburg 2. verbesserte Aufl. 1958) Tafel 77. Vgl. Hermann Hennenberg, Kleriker Würzburger Diözese, 1488 August 26 Neuprovision auf Pfarrkirche Roßdorf Diözese Würzburg 4 Mark nach Tod des Konrad Stramen: ASV $S 89068 v-69 r$. 
sager war 1447 Pfarrer zu Niedernbreit, in Würzburg 1458 Domvikar, Stiftskanoniker, 1463-1468 Pfarrer St. Peter zu Würzburg, stiftete mit Gütern in Niedernbreit die Feier des Dorotheenfests im Würzburger Dom und starb 1475/81 September $4 .^{29}$

Adelige Väter sind relativ selten nachzuweisen. Nur bei drei Personen wird adelige Abstammung ausdrücklich hervorgehoben: Thomas von Neuhaus (de Novadomo) Kleriker Bamberger Diözese 1454 April erweiterte Dispens nobilis coniugatus et soluta, während zuvor auctoritate ordinaria dispensiert, besaß die Kapelle St. Lukas in Kunreuth (Reg. Pen. 4 186r - DN-Antragsnr. 37398); in Bamberg Subdiakon 1454 Juni 15, Diakon 1454 September 21..$^{30}$ Erasmus Rosenberg Scholar Würzburger Diözese 1499 Dezember erweiterte Dispens solutus nobilis et soluta per fiat für drei Pfründen (Reg. Pen. 48 828r DN-Antragsnr. 24145). Christoph Scheyt Scholar Eichstätter Diözese 1507 Juni einfache Dispens solutus nobilis et soluta (Reg. Pen. $53735 v$ - DN-Antragsnr. 26861); verwandt mit Matthias Scheyr, einem natürlichen Sohn des Erzherzogs Sigismund des Münzreichen von Tirol und einer von Westerstetten, deren Wappen er führte, in Paris 1456 baccalaureus, später doctor decretorum, von 1481 bis 1502 Bischof von Seckau, gestorben 1512.31 Hierbei handelte es sich offenkundig um zweifelhafte Fälle; bei bekannten Familien mußte auf den Adel nicht eigens hingewiesen werden. Nach den Familiennamen könnten hierher gehören: Alexander Absperger 1512, Johann und Peter von Exdorf 1449, Johann von Eyb 1449, Johannes Georgii und Paul Johannis von Giech 1463, Johann Henneberger 1485, Erhard und Wilhelm Lesch 1449, Wolfgang und Johann Marschalk 1454/66 und 1465/68, Rudolf von Münkheim 1487, Johann von Romrod 1455, Johann Petri von Rotenhan 1466, Heinrich [Schrimp?] von Berg 1474, Sigismund Seckendorffer 1475, Burkhard und Jakob von Tierberg 1470/73 und 1465/75, Johann Troschler 1454, Jakob Wirsperger 1504 .

29 RG 9 Nr. 3346f.; Engel, Quellen (wie Anm. 3), 183 Nr. 1151; 258 Nr. 1691. Richard Plochmann, Urkundliche Geschichte der Stadt Marktbreit in Unterfranken (Erlangen 1864) 39f., 46; im folgenden zitiert: Plochmann, Marktbreit. Mittelmesse nicht erwähnt bei Bendeh Diözesanmatrikel (wie Anm. 14), 20 Nr. 865: nur Pfarrei und Frühmesse Landkapitel Ochsenfurt. Ivo Fischer, Die Vikarien und Benefizien im Domstift zu Würzburg, in: Würzburger Diözesangeschichtsbll. 3 (1935) 19; Franz Joseph Bendel, Das Bruderschaftsbuch der Ratsbruderschaft an der Marienkapelle in Würzburg aus dem 15. Jahrhundert, in: Würzburger Diözesangeschichtsbll. 7 (1939) 8; Karl Borchardt, Die Jahrtagslisten der Würzburger Dompräsenz von 1450, in: Würzburger Diözesangeschichtsbll. 53 (1991) 129, 149 Anm.; im folgenden zitiert: Borchardt, Jahrtagslisten. Wilhelm Engeh, Das Seelbuch der Liebfrauenbruderschaft zu Würzburg (XII. bis XV. Jahrhunderr) (QFW [wie Anm. 3] 7, Würzburg 1953) 62, 91; Adolar Zumkeller, Urkunden und Regesten zur Geschichte der Augustinerklöster Würzburg und Münnerstadt (QFW [wie Anm. 3] 18, Würzburg 1966/67) 301f., 400, 487; im folgenden zitiert: Zumkeller, Augustinerklöster; Günter Wagner, Kirchenjahr und Meßfeier in der Würzburger Domliturgie des späten Mitrelalters (QFW [wie Anm. 3] 22, Würzburg 1970) 63; Robert Ebner, Das Bruderschaftswesen im alten Bistum Würzburg. Eine Untersuchung unter besonderer Berücksichtigung der geistlichen Bruderschaften der Stadt Kitzingen (Forsch. zur fränkischen Kirchen- und Theologiegesch. 3, Würzburg 1978) 166, 176, 245, 252, 293, 342; im folgenden zitiert: Ebner, Bruderschaftswesen.

${ }^{30}$ Kist, Matrikel (wie Anm. 8), 77 Nr. 1089. Kunreuth bei Forchheim, Patronat der Familienälteste von Egloffstein, 1458 selbständige Pfarrkirche: von Guttenberg, Wendehorst, Bamberg (wie Anm. 13), 113f. Vgl. Ulrich von Neuhaus, 1430 Vikar in Bamberg: Kist, Matrikel (wie Anm. 8), 413 Nr. 6271.

31 Freundlicher Hinweis von Georg Wieland, Konstanz. Nichts über die Abstammung berichtet Benno Roth in: Karl Amon (Hrsg.), Die Bischöfe von Graz-Seckau 1218-1968 (Veröffentlichungen des steiermärkischen Landesarch. 7, Graz/Wien/Köln 1969) 159-193. 
Johann Marschalk ist einer der wenigen nachweisbaren Stiftskanoniker illegitimer Geburt und verdankte diese Stelle sicher seiner adeligen Abkunft. Stiftskanoniker waren ebenfalls Johann Murrer alias Holderlein und Johann Hering. Neben dem Adel ist die städtische Führungsschicht mit Georg Wernitzer und die Beamtenschaft der Territorialherren mit Adam Linck aus Schwabach vertreten, ohne daß den Abkömmlingen damit eine herausragende Karriere geöffnet worden wäre. Obwohl sich angesichts des Forschungsstandes und der Quellenlage die Laufbahn fränkischer Kleriker im 15. Jahrhundert immer nur bruchstückhaft verfolgen läßt, sieht es so aus, als ob auch ein einflußreicher Vater in solchen Fällen keineswegs den Aufstieg verbürgte. Georg Hoeloch, Sohn des Bürgers Hermann Hoeloch aus Ebern, wurde 1441 in Padua doctor decretorum, war Hofkaplan und wichtiger Rat der Bischöfe Gottfried Schenk von Limpurg und Johann von Grumbach in Würzburg und starb 1467 als Stiftsscholaster von Neumünster. Er hatte offenbar einen Sohn, der ebenfalls Georg hieß und dem im Januar 1458 einfache Dispens diaconus et coniugata (Reg. Pen. 6 120v - DN-Antragsnr. 1338) erteilt wurde: sein weiteres Schicksal ist unbekannt. Da er im Testament des Vaters nicht erwähnt wird, mag er früh gestorben sein. ${ }^{32}$ Wichtiger als der Vater konnte mitunter die persönliche Tüchtigkeit sein: Johann Vogt von Dietfurt Eichstätter Diözese Scholar 1457 Oktober einfache, Kleriker 1472 April erweiterte Dispens presbiter et soluta per fiat, besaß Vikarie St. Peter und Paul (Reg. Pen. 6 114r, $20251 \mathrm{r}$ - DN-Antragsnr. 1224, 10088). Er erhielt am 19. August 1472 Dispens, weil er die Pfarrei Stircz [?] Eichstätter Diözese aufgegeben und ohne neue Dispens die Domvikarie St. Peter und Paul zu Eichstätt 5 Mark und das Predigtamt ohne Seelsorge vom Domkapitel erhalten hatte, war außerdem Kanoniker im Willibaldschor zu Eichstätt, Pfarrer Liebenstadt und unter Wilhelm von Reichenau (1464-1496) bischöflicher Notar in Eichstätt, der die erwähnte Diözesanmatrikel von 1480 verfaßte. ${ }^{33}$ Eberhard Senft (Senf) war Hofkaplan Kaiser Maximilians: Scholar Bamberger Diözese 1478 Dezember erste Dispens presbiter et soluta (Reg. Pen. 28 188r DN-Antragsnr. 13635); aus Weismain, Priester Würzburger oder Bamberger Diözese 1492 Erste Bitten König Maximilians auf Zisterzienserinnenkloster Heilsbrück Diözese Speyer, weitere auf St. Ulrich in Augsburg und 1508 auf Benediktinerkloster Kempten, Stiftskanoniker und 1502 -dekan von St. Jakob zu Bamberg, Pfarrer Kirchehrenbach [Verleihung Bischof von Bamberg], Anhänger Luthers, gestorben 1521 Juli $24 .{ }^{34}$

32 Wendehorst, Neumünster (wie Anm. 14), 379f., 556; Georg Ludwig Lehnes, Geschichte des Baunachgrundes in Unterfranken, in: Arch. des HV von Unterfranken 7/1 (1841) 33, 46f.; im folgenden zitiert: Lehnes, Baunachgrund; Helmut Holzapfel, Die Caritas im mittelalterlichen Ebern, in: ZBKiG 23 (1954) 3; RG 7 Nr. 395; RG 8 Nr. 1399: wohl der Vater 1458 November 24 je ein Kanonikat mit Reservation einer Präbende in Theuerstadt außerhalb Bamberg und in St. Marien zu Feuchtwangen Diözese Augsburg, 1459 April 13 Prärogative nicht eingeschriebener Familiaren dabei. Wappen StAW WU 78/378 zu 1467. Im Testament genannt wird sein Neffe Martin. Dr. Martin Hoeloch aus ratsfähiger Familie in Schweinfurt 1494 Vikar und 1520-1525 Kanoniker Neumünster und weitere Pfründen; Wappen StAW WU 87/108 zu 1520.

33 Suttner, Schematismus (wie Anm. 12), IV, VII, X, 28; Scherg, Franconica (wie Anm. 3), 2 242f., Nr. 394.

34 Wachter, Schematismus (wie Anm. 8), 469 Nr. 9499; Kist, Matrikel (wie Anm. 8), 383 Nr. 5848; von Guttenberg, Wendehorst, Bamberg (wie Anm. 13), 115; Ludwig Weiß, Erste Bitten Maximilians I. für das Bistum Würzburg, in: Würzburger Diözesangeschichrsbll. 13 (1951) 105, 113, Nr. 64; 126 Nr. 192; 127 
Manchen Illegitimen gelang es offenbar, den Makel ihrer Geburt kraft eigener Tüchtigkeit im Fürstendienst zu überwinden.

Wenn auch, wie nochmals betont sei, angesichts der Quellenlage und des Forschungsstandes die Karrierechancen der Illegitimen kaum einzuschätzen sind, erhielten doch offenbar die meisten illegitimen Geistlichen nur eine kleine Meßpfründe ohne Seelsorge, allenfalls eine Pfarrkirche, jedoch selten ein Stifts- und nie ein Domkanonikat, ein Offizium, eine Dignität oder gar eine Prälatur. Ihre Pfründeneinkünfte überstiegen selten 4 Mark Silber oder $20 \mathrm{fl}$. Sehr oft lassen sich in den fränkischen Quellen nicht die illegirimen Kleriker selbst, sondern nur ihre mutmaßlichen Väter oder andere Verwandte belegen. Daß man von den Illegitimen selbst wenig hört, mag zum Teil daran liegen, daß sie nicht den Status ihres Vaters erreichten, wie es auch bei den illegitimen Adelssprößlingen (z.B. Eyb) zu beobachten war.

Ohne Anspruch auf Vollständigkeit seien nachfolgend Bemerkungen zu den Illegitimen aus den Pönitentiarie-Registern, ihren möglichen Verwandten und sonstige relevante Belege alphabetisch nach Familiennamen ( $P$ unter B, K unter C, T unter D, Y unter I, V unter F) zusammengestellt:

Alexander Absperger Scholar Eichstätter Diözese 1512 Mai erste Dispens (Reg. Pen. 57 30r - DNAntragsnr. 28849).

Lorenz Adelhofen Scholar Würzburger Diözese 1498 Juli erste Dispens presbiter et soluta (Reg. Pen. 46 $441 v$ - DN-Antragsnr. 23268); 1512 bis 1529 Pfarrer Hohenfeld bei Kitzingen aufgrund Präsentation durch den Propst von Heidenfeld, Mitglied Priesterbruderschaft Kitzingen, hatte selbst drei illegitime Kinder Georg, Andreas und Margarethe, welche 1530 seinen Nachlaß teilten. Kaspar Adelhofen Scholar Würzburger Diözese 1483 April erste Dispens presbiter et soluta (Reg. Pen. 32 205r - DN-Antragsnr. 15741). Michael Adelhofen 1477 bis zum Tod 1494 Vikar im Stift Neumünster zu Würzburg. ${ }^{35}$

Johann Advocati Scholar Würzburger Diözese 1469 April einfache Dispens presbiter et soluta (Reg. Pen. 17 168r - DN-Antragsnr. 7934). Johann Advocati Chorherr bei St. Gangolf zu Bamberg, 1416 Studium Erfurt. $^{36}$

Ulrich Aichnagel Priester Eichstätter Diözese 1462 November einfache Dispens presbiter et soluta per fiat, besaß Pfarrei Möning (Monich) und eine zweite Pfründe (Reg. Pen. 10 304r - DN-Antragsnr. 3948); 1458 November 18 Priester Eichstätter Diözese Surrogation in die Rechte des an der Kurie verstorbenen päpstlichen Familiaren Leonhard Fabri, mit dem er um die Pfarrkirche St. Willibald in Möning [Präsentation Propst des Neuen Kollegs in Spalt] stritt, die 1480 Johann Schimmel nach Tausch auctoritate apostolica besaß. Friedrich Eychennagel 1413 Chorherr von St. Stephan zu Bamberg. ${ }^{37}$

Valentin Altzhofer Scholar Eichstätter Diözese 1464 März einfache Dispens presbiter et soluta (Reg. Pen. 13 247v - DN-Antragsnr. 4692); Kleriker 1469 Frühmesser Mailing Diözese Eichstätt. ${ }^{38}$

Nr. 206; im folgenden zitiert: Weiß, Erste Bitten; Klaus Amold, Johannes Trithemius (1462-1516) (QFW [wie Anm. 3], 23, Würzburg 1971) 271; im folgenden zitiert: Arnold, Trithemius.

35 Eduard Kraus, Hohenfeld am Main. Die Geschichte eines unterfränkischen Dorfes (Würzburg 1933)

113-115; Remling, Bruderschaften (wie Anm. 27), 351; Wendeborst, Neumünster (wie Anm. 14), 696.

${ }^{36}$ Kist, Matrikel (wie Anm. 8), 2 Nr. 13.

37 RG 8 Nr. 5628; Suttner, Schematismus (wie Anm. 12), 29; Kist, Matrikel (wie Anm. 8), 94 Nr. 1325.

38 RG 9 Nr. 6316; Scherg, Franconica (wie Anm. 3), 1118 f., Nr. 274; Sutther, Schematismus (wie Anm. 12), 40: 1480 Johann NN nach Präsentation durch Domdekan zu Eichstätt. 
Johann Andree Priester Würzburger Diözese 1500 Oktober erweiterre Dispens presbiter et soluta per fiat, besaß eine Pfründe (Reg. Pen. $49724 \mathrm{v}$ - DN-Antragsnr. 25459).

Jakob Arzt Scholar Bamberger Diözese 1486 Mai erste Dispens solutus et soluta (Reg. Pen. 35 239v - DNAntragsnr. 17264). Bernhard Arzt licentiatus legum, Domkanoniker Eichstätt, 1485 Kanonikat mit Präbende von Neumünster zu Würzburg, Stiftspropst in Eichstätt, Frühmesser Sulzfeld am Main, gestorben 1525 August 21 als Domherr zu Eichstätt. Bernhard Arzt der Jüngere, Kleriker Augsburger Diözese, prozessierte bis 1506 gegen Konrad von Bibra an der römischen Kurie um ein Domkanonikat mit Präbende zu Würzburg."

Konrad Behringer Scholar Eichstätter Diözese 1453 März erste Dispens presbiter et soluta (Reg. Pen. 4 75v - DN-Antragsnr. 36359); magister in artibus Kleriker 1465 Pfarrei Dasswang [Präsentation durch Bischof von Eichstätt] 8 Mark nach Examen durch Domdekan von Eichstätt, 1466 trotz fälschlicher Angabe magister artium, 1480 bei Martin Molitor. Nicht identisch mit Konrad Behringer 1480 Frühmesser Weidenbach durch Stiftskapitel St. Gumprecht zu Ansbach, geweiht in Augsburg auf sein patrimonium. ${ }^{40}$

Lorenz Peydler Scholar Bamberger Diözese 1454 Juli einfache Dispens presbiter et coniugata (Reg. Pen. 4 212v - DN-Antragsnr. 37569); von Kulmbach, in Bamberg Diakon 1456 Februar 20, Priester 1456 März 13; 1480 Pfarrer Kirchanhausen Eichstätter Diözese durch Domkapitel Eichstätt, stammte aus der Diözese Eichstätt, geweiht jedoch in Bamberg auf Pfarrei Kirchanhausen. ${ }^{41}$

Heinrich [SchrimpP] von Berg Scholar Bamberger Diözese 1474 Oktober erste Dispens presbiter et soluta (Reg. Pen. 23233 - DN-Antragsnr. 11040).

Friedrich Bernhart (Hernhart) Priester Bamberger Diözese 1472 August einfache, 1473 Juli erweiterte Dispens solutus et soluta per fiat während zuvor Defekt verschwiegen, besaß eine Pfründe ohne Seelsorge (Reg. Pen. 20 243r, 21 195v - DN-Antragsnr. 9984, 10650); als Priester 1472 Studium Ingolstadt; vielleicht 1453 Studium Leipzig und dort 1455 baccalaureus artium. ${ }^{42}$

Johann Pfister Akolyth Würzburger Diözese 1468 November einfache Dispens presbiter et soluta, während zuvor Defekt verschwiegen (Reg. Pen. 16 193v - DN-Antragsnr. 7579). Zahlreiche Geistliche dieses Namens, darunter einer als päpstlicher Familiar 1514 Ewigvikar am Magdalenenaltar im Stift Haug nach Tod des Paul Bischoff. ${ }^{43}$

Johann Pilhamer Scholar Eichstätter Diözese 1488 August erste Dispens presbiter et soluta (Reg. Pen. 37 $321 r$ - DN-Antragsnr. 18716). Leonhard Pilhamer, doctor decretorum, Weihbischof zu Eichstätt, und sein Bruder Michael Pilhamer, Pfarrer Weidenbach, beide Priester Regensburger Diözese. 1461 Resignation der Pfarrkirche St. Nikolaus in Kaolberg [?] Diözese Regensburg unter Laienpatronat 6 Mark durch Leonhard zugunsten von Michael, der daneben Frühmesse daselbst 5 Mark besitzt. Leonhard 1464 Resignation der Pfarrei Hechlingen Diözese Eichstätt [Präsentation Bischof von Eichstätt] gegen $40 \mathrm{fl}$ th Jahrespension, 1464 Bischof Microcomien. mit $200 \mathrm{Al}$ th Jahrespension auf Tafelgut des Bischofs Wilhelm von Eichstätt, 1468 Testiererlaubnis über $300 \mathrm{fl} \mathrm{rh}, 1470$ Aushändigung der Urkunde über obige $200 \mathrm{fl}$ rh Pension. ${ }^{44}$

39 1485 Januar 10: ASV S 843 202rv; Engeh Quellen (wie Anm. 3), 265f. Nr. 1748; Kist, Matrikel (wie Anm. 8), 8 Nr. 101; 1506 Oktober 26: ASV V 979 191 r-192r.

40 RG 9 Nr. 897; Scherg, Franconica (wie Anm. 3), 1 69, Nr. 119; 77 Nr. 138; Suttner, Schematismus (wie Anm. 12), 49, 63 .

41 Suttner, Schematismus (wie Anm. 12), 13; Kist, Matrikel (wie Anm. 8), 23 Nr. 286.

42 Kist, Matrikel (wie Anm. 8), 28 Nr. 356.

43 Wilhelm Engel, Ludwig Weiß, Analecta Vaticana Herbipolensia, in: Würzburger Diözesangeschichtsbll.11/12 (1949/50) 196 Nr. 94; im folgenden zitiert: Engel, Weiß, Analecta.

44 RG 8 Nr. 3990; RG 9 Nr. 4390; nichts bei Suttner, Schematismus (wie Anm. 12), 19. 
Paul Bischoff Scholar Würzburger Diözese 1460 Dezember einfache Dispens presbiter et soluta (Reg. Pen. 9 272r - DN-Antragsnr. 2895); Kleriker, päpstlicher Familiar, im 20. Lebensjahr 1461 Pfarrkirche St. Katharina Oppenheim Diözese Mainz 30 lb Tournosen, 1462 dispensatio uberior cum licentia tacendi, im 23. Lebensjahr 1462 Exspektative auf Bamberg sowie Stift Haug in Würzburg, Ewigvikarie am Marienaltar in Pfarrkirche Waldorp [?] Diözese Köln 4 Mark, päpstlicher Palafrenar 1463 Mittelmesse Niedernbreit Diözese Würzburg 4 Mark ungeachtet Laienpatronat (wie Johann Herdigen oben Anm. 29), Kanonikat mit Präbende in Heiligenstadt Diözese Mainz 7 Mark und in St. Peter zu Zeitz Diözese Naumburg 6 Mark (gegen $20 \mathrm{fl}$ Pension resigniert), 1464 Kanonikat mit Präbende in St. Cyriakus außerhalb Worms 6 Mark, kraft seiner Exspektativen Ewigmesse im Dom zu Bamberg 5 Mark und streitig Allerheiligenaltar im Stift Haug 3 Mark, Domvikar in Mainz, 1487 Pfarrer Willanzheim Diözese Würzburg, als vicarius senior am Magdalenenaltar im Stift Haug 1514 September 21 verstorben. Paul Muller alias Bischoff Scholar Würzburger Diözese 1488 April erste Dispens presbiter et soluta (Reg. Pen. 37 317r - DN-Antragsnr. 18519); als Familiar des päpstlichen Sekretärs Paul Tuba 1502 August 5 Dispens für zwei inkompatible Benefizien (L $11153 r-4 v$ ) und 1510 Juli 2 neben der Frühmesse Grafentheinfeld die Pfarrkirche Freudenbach Diözese Würzburg 4 Mark (V 962 160r-63r). Johann Bischoff Kleriker aus Speyer 1458 Familiar von Pius II., Kanoniker von St. Germanus und Mauritius zu Speyer, gestorben vor 1489 Mai 20. Johann Muller alias Bischoff (Bistoff) Scholar Würzburger Diözese 1480 Januar und 1486 Oktober erste Dispens solutus bzw. presbiter et soluta (Reg. Pen. 29 192v, 36 315v - DN-Antragsnr. 14190, 17577). Die Brüder Johann und Michael Bischoff Scholaren Würzburger Diözese 1485 April erste Dispens presbiter et soluta (Reg. Pen. 34 270r - DN-Antragsnr. 16635-36). Johann Muller alias Bischoff (welcher?) 1491 Ewigvikarie am Marienaltar in Pfarrkirche Bettingen Diözese Würzburg 2 Mark nach Resignation des Johann Baunach (Barench). Michael Bischoff Priester Würzburger Diözese 1491 Neuprovision auf Ewigvikarie missa animarum in Pfarrkirche St. Veit zu Iphofen Diözese Würzburg 4 Mark nach Resignation des Jodokus Winter und des Johann Bischoff; 1497 Vikar in Iphofen. Paul Bischoff 1522-46 Domvikar Bamberg. ${ }^{45}$

Willibald Pistoris Scholar Eichstätter Diözese 1461 Mai einfache Dispens presbiter et soluta (Reg. Pen. 10 266v - DN-Antragsnr. 3677); Willibald Piscator (Fischer) 1480 Sekretär des Bischofs von Eichstätt. Johann Pistoris Scholar Eichstätrer Diözese 1492 Seprember erste Dispens solutus et soluta (Reg. Pen. 42 258vDN-Antragsnr. 21029); Johann Pistor(is) 1480 Vikar in der Dreifaltigkeitskapelle des Doms zu Eichstätt, Vikar in Pfarrkirche Berching, ordiniert auf den Freiherrn von Heideck. Johann Pistoris ebenfalls mehrere Geistliche, darunter einer Studium Leipzig, dann Stiftsherr in Soldin bei Frankfurt/Oder. ${ }^{46}$

Georg Plachseiber Kleriker Würzburger Diözese und anwesend an der römischen Kurie 1492 November erweiterte Dispens presbiter et soluta, während zuvor auctoritate ordinaria dispensiert, besaß den Altar St. Maria Magdalena in der Kirche St. Johannis in Künzelsau (Reg. Pen. $42291 \mathrm{r}$ - DN-Antragsnr. 21451).

45 RG 8 Nr. 2557, 4730; RG 9 Nr. 5238; 1489 Mai 20: S 903 245v; 1491 April 28: S 93681 rv; 1491 August 29: S 942 82r; Wachter, Schematismus (wie Anm. 8), 49 Nr. 894; Kist Matrikel (wie Anm. 8), 40 Nr. 518; Bendel, Diözesanmatrikel (wie Anm. 14), 5 Nr. 156; Engel, Weiß, Analecta (wie Anm. 43), 193 Nr. 65; 196 Nr. 94; Ph. Emil Ullrich, Liber regulae ecclesiae Haugiensis, in: Arch. des HV von Unterfranken 29 (1886) 303; im folgenden zitiert: Ullrich, Liber regulae; Theobald Freudenberger, Quellen zur Geschichte der Wallfahrt und des Augustinerchorherrenstiftes Birklingen bei Iphofen (Mainfranken) 14571546, in: Würzburger Diözesangeschichtsbll. 5 (1937) 142.

46 Suttner, Schematismus (wie Anm. 12), VIIf., 8; Ludwig Weiß, Würzburger Bistumsangehörige als Weihekandidaten in Merseburg 1470-1556, in: Würzburger Diözesangeschichtsbll. 18/19 (1956/57) 184; im folgenden zitiert: Weiß, Weihekandidaten. 
Dietrich Plessener (Plestener) Würzburger Diözese 1450 September einfache Dispens presbiter et soluta (Reg. Pen. 4 43r - DN-Antragsnr. 35063); in Rom 1450 Dezember 19 erste Tonsur und Akolyth, 1451 März 20 Subdiakon, 1451 April 24 Diakon. ${ }^{47}$

Johann BoldI Kleriker Würzburger Diözese 1499 Dezember erweiterte Dispens presbiter et soluta per fiat, besaß Ewigpfründe am Altar St. Marien im Benediktinerkloster St. Egidien zu Nürnberg (Reg. Pen. 48 876v - DN-Antragsnr. 24710).

Die Brüder Johann und Kaspar Brunner Scholaren Würzburger Diözese 1491 Juli erste Dispens presbiter et soluta (Reg. Pen. 40 514r - DN-Antragsnr. 20273f.). Johann Brunner Chorherr St. Stephan zu Bamberg. Johann Brunner Pfarrer Oberkotzau. Konrad Brunner bis zum Tod 1495 Vikar St. Leonhard im Stift Ansbach. ${ }^{48}$

Leonhard Bucherer Scholar Bamberger Diözese 1451 Januar erste Dispens solutus et soluta (Reg. Pen. 4 $50 \mathrm{v}$ - DN-Antragsnr. 35700). Leonhard Bucher von Winczelhusen [?] 1474/75 Studium Basel.99

Johann Kammerzell Kleriker Würzburger Diözese 1463 Oktober erweiterte Dispens presbiter et soluta per fiat, war Altarist am Marienaltar des Spitals vor den Toren von Kolluper [?] (Reg. Pen. 11 378r - DNAntragsnr. 4580).

Georg Carnificis Eichstätter Diözese Scholar 1459 Oktober einfache, Priester 1479 März erweiterte Dispens solutus et soluta per fiat, besaß Pfründe ohne Seelsorge (Reg. Pen. 7 328v, 28 302v - DN-Antragsnr. 2149, 13964); Georg Metzger $148410 \mathrm{fl}$ rh Pension durch Äbtissin des Benediktinerinnenklosters Heiligkreuz zu Bergen Diözese Eichstätt nach Resignation der Kaplanei des Klosters. ${ }^{50}$

Johann Karolo Scholar Eichstätter Diözese 1486 Oktober erste Dispens solutus et soluta (Reg. Pen. 36 315r - DN-Antragsnr. 17561). Carolus filius Caroli Scholar Eichstätter Diözese 1491 April erste Dispens clericus et soluta (Reg. Pen. 40 505v - DN-Antragsnr. 20149). Leonhard Caroli Scholar Bamberger Diözese 1502 Dezember und 1511 Juli jeweils erste Dispens expositus et exposita in ecclesia sive hospitali bzw. presbiter et soluta (Reg. Pen. 50 626r, 56 835r - DN-Antragsnr. 26044, 28410).

Ulrich Castner Akolyth Würzburger Diözese 1485 November erste Dispens presbiter et soluta (Reg. Pen. 35 218v - DN-Antragsnr. 17006); Kleriker 1491 Erste Bitten König Maximilians auf Stift St. Marien in Erfurt. Ulrich Castner, Pfarrer zu Oberaspach bei Schwäbisch Hall, wurde durch die Grafen Kraft V. und Albrecht II. von Hohenlohe 1459 auf die Frühmesse in Oberstetten präsentiert und konnte sich 1465 gegen den von der Reichsstadt Rothenburg präsentierten Kaspar Schwertfeger durchsetzen, der freilich erst 1471 verzichtete. Ulrich Castner aus der Diözese Augsburg 1480 Pfarrer in Absberg Diözese Eichstätt [Präsentation Engelhard von Absberg], zuvor Vikar in Röckingen, ordiniert in Merseburg. Konrad Kastner erhielt 1437 Dispens super defectu natalium und wurde 1443 aufgrund Präsentation durch Georg von Likartshausen Kaplan in Goldbach bei Crailsheim. ${ }^{51}$

47 RG 6553, Nr. 5431.

48 Kist, Matrikel (wie Anm. 8), 56 Nr. 762f.; von Guttenberg, Wendehorst, Bamberg (wie Anm. 13), 247f.; Wilhelm Engel, Die Seelbücher des Kollegiatstiftes St. Gumbert in Ansbach (XI. bis XVI. Jahrhundert) (QFW [wie Anm. 3], 3 [Würzburg 1950]) 48, 83 Nr. 402.

49 Ludwig Weiß, Baseler Studenten aus dem Bistum Würzburg 1460-1529, in: Würzburger Diözesangeschichtsbll. 16/17 (1954/55) 233.

50 Scherg, Franconica (wie Anm. 3), 3 159f., Nr. 920.

51 Weiß, Erste Bitten (wie Anm. 34), 111 Nr. 41; Borchardt, Rothenburg (wie Anm. 22), 584 Nr. 292; RG 8 Nr. 5639; Suttner, Schematismus (wie Anm. 12), 17, 73; Wilhelm Engel, Urkundenregesten zur Geschichte der kirchlichen Verwaltung des Bistums Würzburg im hohen und späten Mittelalter (11361488) (QFW [wie Anm. 3], 9, Würzburg 1954) 222; im folgenden zitiert: Engel, Urkundenregesten; Gustav 
Johann Keyser Scholar Würzburger Diözese 1450 September einfache Dispens presbiter et coniugata (Reg. Pen. 4 43r - DN-Antragsnr. 35062); Priester 1452 Pfarrei Lauffen Diözese Würzburg 25 f rh und Pfarrei St. Marien Aschach [?] Diözese Augsburg 6 Mark. ${ }^{52}$

Anton Keuler (Keyler, Kewller, Kewler) Bamberger Diözese 1493 November erste, 1499 Juli erweiterte Dispens solutus et soluta per fiat für zwei Pfründen, besaß eine Pfründe in Rentweinsdorf (Rompelsdorf) Diözese Würzburg (Reg. Pen. 43 388r, $47619 \mathrm{v}$ - DN-Antragsnr. 21537, 23981); 1495 aufgrund Präsentation durch Gottfried von Rotenhan Vikar der Kapelle in Rentweinsdorf Diözese Würzburg, 1518 und 1527 Vikar St. Bartholomäus in Domsepultur Bamberg, Präsentation durch Ältesten von Rotenhan, gestorben 1550 Juni 29, vermachte $200 \mathrm{fl}$ dem Franziskanerkloster zu Bamberg. ${ }^{53}$

Ulrich Klawber Scholar Eichstätter Diözese 1483 März erste Dispens presbiter et coniugata (Reg. Pen. 32 202v - DN-Antragsnr. 15638); 1480 Vikar im Neuen Kolleg zu Spalt Diözese Eichstätt. ${ }^{54}$

Pankraz Knorn Scholar Bamberger Diözese 1480 März erweiterte Dispens presbiter et soluta (Reg. Pen. 29 195r - DN-Antragsnr. 14252). Pankraz Knor von Eggolsheim 1508 Studium Leipzig, in Merseburg Priester 1512 April 10.55

Jodokus Kolpffel Scholar Würzburger Diözese 1501 September erste Dispens solutus et soluta (Reg. Pen. 50 329r - DN-Antragsnr. 25573). Johann Klüpfel Bakkalaureus, später Lizenziat beider Rechte, 1478 bis 1485 an der römischen Kurie, 1478 Kanonikat mit Präbende 9 Mark im Stift Haug zu Würzburg nach Resignation durch Georg Klüpfel, welchem dies 1477 verliehen worden war, ohne daß es durchgeführt werden konnte, 1481 Pfarrer zu Haug, 1483 Prärogativen eingeschriebener Familiaren, 1484 im Dienst des päpstlichen Korrektors Bischof Celsus Millini von Montefeltro, Ewigvikarie am Apostelaltar im Dom zu Würzburg (1486 nach Resignation durch Valentin Klupfel 4 Mark, welcher als Kleriker Würzburger Diözese damals Erste Bitten durch König Maximilian auf Eichstätt), Pfarrer Ornbauer Diözese Eichstätt 9 Mark, 1485 Subdiakon Priesterweihe in Rom, aufgrund Exspektative Kanonikat mit Präbende St. Burkhard zu Würzburg 8 Mark, Frühmesser Winterhausen 4 Mark, 1486 Pfarrer Winterhausen 10 Mark, gestorben 1535 als Pfarrer zu Niedernbreit, Jahrtag Haug November 23 und Stiftung zum Hieronymusfest. ${ }^{56}$

Konrad Kolb Priester Würzburger Diözese 1453 September erweiterte Dispens presbiter et soluta per fiat besaß eine Pfründe ohne Seelsorge (Reg. Pen. 4 167r - DN-Antragsnr. 37278).

Johann Koeller Scholar Würzburger Diözese 1464 Oktober erste Dispens presbiter et soluta (Reg. Pen. 13 272v - DN-Antragsnr. 5619). Aus Ebern, 1463 Studium Leipzig, 1472 Diakon in Merseburg, Mitglied der

Bossert, Zur Geschichte der Archidiakone und Generalvikare der Diözese Würzburg, in: Arch. des HV von Unterfranken 29 (1886) 349f.; Beschreibung des Oberamts Crailsheim (Stuttgart 1884, ND 1967) 267.

52 RG 6277, Nr. 2683.

53 Helmut Holzapfel, Bayrisch-fränkische Bruderschaftsbücher des Mittelalters, H. 2: Die Priesterbruderschaft an der Baunach (Nürnberg 1953) 52; im folgenden zitiert: Holzapfel, Baunach; Bendel Diözesanmatrikel (wie Anm. 14), 3 Nr. 76; Wachter, Schematismus (wie Anm. 8), 252 Nr. 5169; Kist, Matrikel (wie Anm. 8), 218 Nr. 3274; von Guttenberg, Wendehorst, Bamberg (wie Anm. 13), 64.

54 Suttner, Schematismus (wie Anm. 12), 66.

55 Kist, Matrikel (wie Anm. 8), 224 Nr. 3378.

56 Engeh, Quellen (wie Anm. 3), 241 Nr. 1571, 269 Nr. 1769; 1484 September 12: ASV V 683 75rv; 1484 Dezember 30: S 843 183v; 1485 Januar 8: L 840 69r-70v; 1485 April 26: $S 846$ 26r; 1485 Mai 17: S 846 220r; 1485 Dezember 7: S 852 288r, L 850 69v-7I r; 1486 Januar 17; S 853 191r; 1486 Januar 26: S 854 72v; 1486 Februar 10: S 854 264v-65r; 1486 Februar 21: S 854 299r; 1486 März 10: S 855 227r; 1486 April 11: S 856 194r; 1486 Oktober 7: S 862 53r; Ullrich, Liber regulae (wie Anm. 45), 305, 316; Weifs Erste Bitten (wie Anm. 34), 110 Nr. 30; Johannes Wenzeh Marktbreit: Geschichte einer kleinen fränkischen Stadt (Markbreit 1987) 68. 
Priesterbruderschaft Baunach, 1487 Frühmesser Unterschüpf. Johann Keller, Kleriker Würzburger Diözese, Familiar des Kardinalbischofs Rodrigo von Porto, erbat und erhielt, nachdem einst der Kardinallegat Francesco Todeschini-Piccolomini seinen Fall untersucht hatte, 1486 Dispens presbiter et soluta und Habilität zum Pfründenerwerb. ${ }^{57}$ Johann Koler Scholar Würzburger Diözese 1500 September erste Dispens presbiter et soluta (Reg. Pen. 49 676r - DN-Antragsnr. 24851).

Nikolaus Kraft Scholar Eichstätter Diözese 1481 November erste Dispens solutus et soluta (Reg. Pen. 31 205v - DN-Antragsnr. 14996). Johann Kraft Kleriker Würzburger Diözese 1517 Februar einfache Dispens presbiter et soluta (Reg. Pen. 60 404v - DN-Antragsnr. 29767). Johann Kraft zwischen 1480 und 1490 Pfarrer Stadtschwarzach. ${ }^{58}$

Wolfgang Kraus (Krawsz, Krawiser) Eichstätter Diözese Scholar 1499 Oktober erste, Kleriker 1501 Juli erweiterte Dispens diaconus et soluta per fiat besaß eine Pfründe (Reg. Pen. 48 815r, 49 743v - DNAntragsnr. 24030, 25543).

Martin Creisser Scholar Würzburger Diözese 1461 Mai einfache Dispens presbiter et soluta (Reg. Pen. 9 302v - DN-Antragsnr. 3132). Martin Kreysser 1500-1519 Pfarrer Stetten vor der Rhön [1483 eingerichtet]. Michael Kreyser 1496-1526 Pfarrer Fladungen von der Rhön. ${ }^{59}$

Peter Kurndorffer Scholar Bamberger Diözese 1486 April erste Dispens presbiter et soluta (Reg. Pen. 35 238r - DN-Antragsnr. 17226). Nikolaus Kurndorffer von Münchberg Priester 1453 März 31, Pfarrer Ahornberg 1469 Oktober $20 .^{60}$

Die Brüder Johann und Lorenz Taurenfelder von Freystadt (Freyenstar) Scholaren Eichstätter Diözese 1454 Mai einfache Dispens presbiter et soluta (Reg. Pen. 4 189rv - DN-Antragsnr. 37423-24). Berthold Taurenfelder Kleriker Eichstätter Diözese 1457 Juli 16 erweiterte Dispens presbiter et soluta mit licentia tacendi, im 22. Lebensjahr 1459 Familiar des päpstlichen Thesaurars Bischof Nikolaus von Teano zwei Exspektativen auf Eichstätt und Augsburg, 1462 Familiar des Kardinals Nikolaus von S. Cecilia, 1463 Pfarrkirche S. Antonio zu Fano 50 lb Tournosen, 1464 kraft Exspektative Pfarrer Lellenfeld Diözese Eichstätt [Präsentation Bischof von Eichstätt], Palafrenar des Kardinals, Erlaubnis, sich für drei Jahre nicht zum Priester weihen zu lassen, Exspektativen auf Augsburg und Benediktinerkloster St. Ulrich in Augsburg, Domvikarie Augsburg 3 oder 4 Mark, Laurentiusaltar in Pfarrkirche Schlettstadt Straßburger Diözese 4 Mark, in Rom 1465 März 9 Subdiakon, 1465 März 30 Diakon, 1466 Juni 6 Priester. ${ }^{61}$

Arnold Decker (Deckerer, Dokner) Eichstätter Diözese Scholar 1501 April einfache, Kleriker 1507 April erweiterte Dispens presbiter et soluta (Reg. Pen. 49 707r, 53 723r - DN-Antragsnr. 25310, 26696). Sebald Decker aus Hersbruck, ordiniert in Bamberg und Zeitz auf die Pfinzing in Nürnberg, 1480 erster Cooperator der Pfarrei St. Veit Kottingwörd. ${ }^{62}$

57 Weiß, Weihekandidaten (wie Anm. 46), 155; Holzapfeh Baunach (wie Anm. 53), 35, 77f. mit Anm. 414; Oskar Friedlein, Die kirchlichen Verhältnisse im Oberamt Boxberg und im Schüpfergrund vor der Reformation, in: Würzburger Diözesangeschichtsbll. 31 (1969) 160; 1486 Februar 21: ASV S 856171 rv.

58 Engel, Urkundenregesten (wie Anm. 51), 274; Ebner, Bruderschaftswesen (wie Anm. 29), 101.

59 Michael Müller, Das Landkapitel Mellrichstadt, Franconia Sacra. Geschichte und Beschreibung des Bisthums Würzburg. Begonnen v. Johann Baptist Stamminger, fortgeserzt von August Amrhein (Würzburg 1901) 265; Helmut Holzapfeh, Kirchliches und städtisches Leben in Fladungen v. d. Rhön bis zum Ende des 30-jährigen Krieges (Würzburg 1940) 33.

60 Kist, Matrikel (wie Anm. 8), 247 Nr. 3760; von Guttenberg, Wendehorst, Bamberg (wie Anm. 13), 205.

61 RG 7 31, Nr. 270; RG 8 Nr. 502; RG 9 Nr. 581; Suttner, Schematismus (wie Anm. 12), 71.

62 Suttner, Schematismus (wie Anm. 12), 13. 
Thomas Thome von Dürn (Duru) Scholar Würzburger Diözese 1469 November erste Dispens presbiter et soluta (Reg. Pen. 17 179v - DN-Antragsnr. 8239). Thomas Thome de Westein aus Walldürn Studium des Kirchenrechts 1426 Köln, Hofmeister des Konrad Schenk von Limpurg, 1427 Pfarrer Eutendorf Diözese Würzburg. ${ }^{63}$

Jakob von Tierberg Würzburger Diözese Scholar 1465 Mai einfache, Kleriker 1475 April erweiterte Dispens presbiter et soluta per fiat war Ewigvikar der Kapelle St. Leonhard in Schwäbisch Hall (Reg. Pen. 12 149v, 23 225r - DN-Antragsnr. 5224, 11281); 1473 durch Kaiser Friedrich III. Befehl zur Verleihung einer Pfründe durch den Pfarrer zu Heilbronn, 1486 Erste Bitten König Maximilians auf Stift Surburg Diözese Straßburg, 1490 erweiterte Dispens presbiter et soluta für zwei inkompatible Benefizien, während zuvor durch den legatus de latere Bischof Bartholomäus von Città di Castello dispensiert, Stiftskustos von St. Michael zu Klingenmünster Diözese Speyer. Burkhard von Tierberg Würzburger Diözese Scholar 1470 Mai erste, Priester 1473 April erweiterte Dispens presbiter et soluta per fiat (Reg. Pen. 18 245r, 21 193r DN-Antragsnr. 8639, 10616); 1486 Erste Bitten König Maximilians auf Stift Weißenburg Diözese Speyer, 1490 Ewigvikar der Stiftskirche St. Michael zu Klingenmünster, 1490 Neuprovision auf Pfarrkirche St. Johann zu Weißenburg Diözese Speyer 10 Mark nach Tod des Ägidius von Zabern und Akzeptation aufgrund Erster Bitten König Maximilians (dabei erwähnt Dispense presbiter et soluta und ad duo incompatibilia durch die Pönitentiarie und dann durch den verstorbenen Bischof Bartholomäus von Città di Castello, legatus de latere) ungeachtet der Tatsache, daß gleichzeitig für über drei Monate Pfarrkirche Butzfeld [?] Diözese Würzburg 6 Mark. ${ }^{64}$

Johann Dilthey Scholar Würzburger Diözese 1474 April erste Dispens presbiter et soluta (Reg. Pen. 22 190r - DN-Antragsnr. 10946). Heinrich Dilthey 1473 Domvikar Würzburg, 1473 und 1485 Pfarrer Rieneck. Hermann Dilthey 1480 Domvikar Würzburg. ${ }^{65}$

Johann Dolder Scholar Würzburger Diözese 1468 Dezember einfache Dispens presbiter et soluta $($ Reg. Pen. 16 194v - DN-Antragsnr. 7608); 1488 Domornatmeister in Würzburg. Johann Dolder Zisterzienser in Ebrach, 1465 Pfarrer Burgwindheim. Philipp Dolder nach 1469 und bis 1505 Pfarrer Gramschatz. ${ }^{66}$

Peter Dorn Scholar Bamberger Diözese 1493 Oktober erste Dispens presbiter et soluta (Reg. Pen. 43 386r DN-Antragsnr. 21537); Peter Dorn 1469 Engelmesser Ebermannstadt. ${ }^{67}$

Johann Troschler und sein ungenannter Bruder Scholaren Würzburger Diözese 1454 Februar einfache Dispens presbiter et soluta (Reg. Pen. 4 128r - DN-Antragsnr. 37004f.). Friedrich Troschler aus der Diözese

63 Engel, Quellen (wie Anm. 3), 165f. Nr. 1035, 167f. Nr. 1041; August Amrhein, Gottfried IV. Schenk von Limpurg, Bischof von Würzburg und Herzog zu Franken 1442-1455, in: Arch. des HV von Unterfranken 50 (1908) 45; Bendeh Diözesanmatrikel (wie Anm. 14), 11 Nr. 449.

64 Weiß, Erste Bitten (wie Anm. 34), 121 Nr. 146, 154; Carl Gottfried Scharold, Auszüge aus den Urkunden des röm. Kaisers Friedrich III., in: Arch. des HV von Unterfranken 6/2 (1840) 12; Jakob de Trebres 1490 November 5: ASV S 926 151r; 1490 Februar 13: S 916 212rv; 1490 September 19: S 924 34r; 1490 September 22: S 924 39v; 1490 Dezember 2: $S 933$ 241v (Burkhard), 242r (Jakob).

65 Michael Wieland, Beiträge zur Geschichte der Grafen, Grafschaft, Burg und Stadt Rieneck, in: Arch. des HV von Unterfranken 20/1-2 (1869) 194, 300-302; im folgenden zitiert: Wieland, Rieneck.

66 Verzeichnis der sämtlichen Erwerbungen für die Vereinssammlungen, in: Arch. des HV von Unterfranken 6/2 (1840) XVIII; Otto Schnell, Beiträge zur Geschichte des Marktfleckens Burgwindheim, in: Arch. des HV von Unterfranken 25/2-3 (1881) 397, 418; Klaus Guth, Das Entstehen fränkischer Wallfahrten, in: MainfrJb 29 (1977) 43; Georg Schwinger, Das St. Stephans-Kloster O.S.B. in Würzburg. Beiträge zu dessen Geschichte, in: Arch. des HV von Unterfranken 41 (1899) 191.

67 Wachter, Schematismus (wie Anm. 8), 90 Nr. 1691; von Guttenberg, Wendehorst, Bamberg (wie Anm. 13), $127 \mathrm{f}$. 
Würzburg ordiniert in Erfurt auf die Dreikönigskaplanei in St. Bartholomäus daselbst, 1461 Stiftskanoniker und -kantor St. Gumprecht zu Ansbach, Pfarrer Henfenfeld Diözese Eichstätt [Präsentation Abt von Michelfeld], Erlaubnis, dort nicht persönlich zu residieren, 1475-1480 Pfarrer Sammenheim Diözese Eichstätt [Präsentation Abt von Heidenheim]. ${ }^{68}$

Johann Duwer Scholar Würzburger Diözese 1453 Januar erste Dispens solutus et soluta (Reg. Pen. 4 74r DN-Antragsnr. 36282). Johann Duwerk Scholar Würzburger Diözese 1452 Januar erweiterte Dispens solutus et soluta (Reg. Pen. 4 62v - DN-Antragsnr. 36165). Johann Dawer (Duwer, Dawr) Utrechter Kleriker, doctor decretorum, Kanoniker St. Stephan zu Mainz und Haug 1431-1449, 1432 dem Basler Konzil inkorporiert, Jahrtag im Stift Haug zu Würzburg Juni 24. ${ }^{69}$

Johann Ekart (Eckart) Würzburger Diözese 1450 März einfache Dispens solutus et soluta (Reg. Pen. 4 30r DN-Antragsnr. 34020); unter Pius Il. (1458-1464) Pfarrer Taschendorf Diözese Würzburg. ${ }^{70}$

Johann von Eyb Scholar Eichstätter Diözese 1449 April einfache Dispens diaconus et soluta (Reg. Pen. 4 14v - DN-Antragsnr. 33403). Johann von Eyb, von beiden Eltern aus ritterlichem Geschlecht, war Domkanoniker zu Eichstätt, Würzburg und Bamberg, licentiatus in decretis, Rat des Markgrafen Albrecht Achilles, 1447 Domscholaster Eichstätt und Pfarrer Dollnstein Diözese Eichstätt, 1448 Dompropst Bamberg, Domkanoniker Würzburg, 1450 Domdekan Bamberg, 1453 Propst des Neuen Kollegs in Spalt, 1455 Dompropst Eichstätt und Stiftspropst Herrieden, 1459 Domkellerer Bamberg, Stiftspropst von St. Gumprecht zu Ansbach und starb 1468 August 22. ${ }^{71}$

Jakob Eich Kleriker Bamberger Diözese 1452 Mai erweiterte Dispens solurus et coniugata, während zuvor auctoritate ordinaria dispensiert (Reg. Pen. $478 \mathrm{v}$ - DN-Antragsnr. 36454).

Johann (Scholar) und Peter von Exdorf Würzburger Diözese 1449 April bzw. beide Juni einfache Dispens presbiter et soluta (Reg. Pen. 419v, 20r - DN-Antragsnr. 33539, 33554, 33555).

Johann Fabri Kleriker Würzburger Diözese 1488 August erste Dispens presbiter et soluta mit Kommission an den an der römischen Kurie lebenden Bischof von Agrigent (Reg. Pen. 37 323r - DN-Antragsnr. 18712). Johann Fabri von Fulda Kleriker Würzburger Diözese bis zu seiner Resignation 1489 sacre penitentiarie apostolice procurator, dann litterarum apostolicarum sollicitator und 1490 Pfarrer Schlitz Diözese Mainz 4 Mark; als causarum procurator 1491 Dispens für drei inkompatible Benefizien; 1491 Stiftskanonikat mit Präbende von St. Marien zu Erfurt 8 Mark nach Resignation des Grafen Friedrich von Büdingen; 1491 Änderung seiner Exspektativen, so daß neben Pfründe durch Kloster Fulda künftig Kanonikar von St. Andreas Novimon. [?] Diözese Mainz statt von St. Viktor zu Mainz. Johann Fabri (welcher?) resignierte 1490 die Frühmesse zu Helmstadr Diözese Würzburg 3 Mark zugunsten des päpstlichen Familiaren Heinrich Palmer. ${ }^{72}$ Johann Fabri Scholar Würzburger Diözese 1495 April erste Dispens presbiter et soluta (Reg. Pen. 44 365v - DN-Antragsnr. 22272). Nikolaus Fabri Scholar Würzburger Diözese 1475 November erste

68 RG 8 Nr. 1219; Suttner, Schematismus (wie Anm. 12), 3, 20. Vielleicht Niederadel.

69 RG $673, \mathrm{Nr}$. 689; 451 Nr. 4438; Jakob Kübles, Das Stifthauger Dekanatsbuch, in: Arch. des HV von Unterfranken 21/3 (1872) 66; Ullrich, Liber regulae (wie Anm. 45), 286; Engel, Quellen (wie Anm. 3), 175 Nr. 1091; Theobald Freudenberger, Würzburg zur Zeit des Konzils von Basel 1439-1443, in: Würzburger Diözesangeschichtsbll. 50 (1988) 85, 91 Anm. 32, 93 Anm. 44, 94.

70 ASV L 540 166v: RG 8 Nr. 2757 [unvollständiger Eintrag].

71 RG 6 292f., Nr. 2821; RG 7 160, Nr. 1423; RG 8 Nr. 2765; Wachter, Schematismus (wie Anm. 8), 116 Nr. 2266; Eberhard Frhr. $\nu$. Eyb, Das reichsritterliche Geschlecht der Freiherrn von Eyb (Veröffentlichungen der Ges. für fränkische Gesch. IX/29, Neustadt/Aisch 1984) 72-77 Nr. 32.

721489 Juli 2: ASV S 905 160v; 1490 September 23: S 924 243v; 1491 Januar 28: S 930 230r; 1491 März 28: S 934 105rv; 1491 Dezember 12: S 947 195v-196r; 1490 Januar 31: S 915 33v-34r. 
Dispens presbiter et soluta (Reg. Pen. 24 205v - DN-Antragsnr. 12292). Veit Fabri Scholar Eichstätter Diözese 1475 Oktober erste Dispens presbiter et saluta (Reg. Pen. 24 202r - DN-Antragsnr. 12197). Johann Veyel (Feyel, Veijal) Kleriker Eichstätter Diözese 1452 September erweiterte Dispens presbiter et soluta per fiat für zwei Pfründen (Reg. Pen. 4 67r - DN-Antragsnr. 36210); Johann Feyel (Veyel, Veyal, Veyol, Vexal) 1442-1446 Pfarrer Herzogenaurach, 1444 Studium Leipzig, 1452 Kanonikat und Präbende St. Andreas zu Freising 10 Mark und Pfarrei St. Marien [!] zu Windsbach Diözese Eichstätr 12 Mark [Verleihung durch Bischof von Bamberg], 1452 fälschlich totgesagt bei Pfarrkirche Roth 6 Mark, 1453 Pfarrkirche St. Veit Ottensoss 7 Mark, 1457 Domvikar Eichstätt, Pfarrer Breid Diözese Eichstätt. ${ }^{73}$

Michael Feldner Kleriker Würzburger Diözese 1494 März erste Dispens presbiter et soluta, während zuvor Defekt verschwiegen (Reg. Pen. 43 399v - DN-Antragsnr. 21741). Michael Feldner, ordiniert in Eichstätt auf Markgraf Albrecht Achilles, 1480 Kaplan der Burgkapelle in Heideck [Präsentation des Markgrafen]. ${ }^{74}$ Johann Vetter Scholar Eichstätter Diözese 1519 November erste Dispens presbiter et soluta (Reg. Pen. 65 405r - DN-Antragsnr. 30780). Johann Vetter aus Uffenheim Kleriker Würzburger Diözese 1471 Frühmesse Hohebach Diözese Würzburg 2 Mark, 1501 Pfarrei Geiselwind, gestorben vor 1503. Friedrich Vetter 1480 Propst von Heiligkreuz außerhalb der Mauern von Eichstätt Benediktinerordens. ${ }^{75}$

Die Brüder Gregor und Johann Vinck Scholaren Würzburger Diözese 1462 Dezember einfache Dispens presbiter et soluta (Reg. Pen. $10281 \mathrm{r}$ - DN-Antragsnr. 3849, 3850); in forma pauperum als Kleriker Exspektativen 1465 April 1 [fiktives Datum] für Gregor auf Domdekan und -kapitel Augsburg, für Johann auf Stift St. Burkhard zu Würzburg. Gregor 1463 Kleriker und Pfarrer St. Laurentius zu Dornheim Diözese Würzburg 4 Mark, in Rom 1465 März 9 Subdiakon, 1465 Juni 8 Diakon, 1465 September 21 Priester. Johann Finck zwischen 1480 und 1490 Engelmesser Niedernbreit, Nikolaus Finck Pfarrer Sulzfeld. ${ }^{76}$

Thomas Vinder von Hilpoltstein Scholar Eichstätter Diözese 1451 Januar erste Dispens presbiter et soluta (Reg. Pen. 4 50r - DN-Antragsnr. 35691); ordiniert in Eichstätt auf Pfarrei Berolzheim, 1480 Frühmesser St. Walpurgis in Monheim nominiert durch Reichsstadt Rothenburg und präsentiert durch Äbtissin von Monheim. ${ }^{77}$

Johann Vischer Würzburger Diözese 1452 Dezember erste Dispens solutus et soluta (Reg. Pen. 473v - DNAntragsnr. 36255); 1474 Pfarrer Schlüsselfeld, Vikar Thunfeld, Dekan Haßlach. ${ }^{78}$

Matthäus Fleischmann Scholar Würzburger Diözese 1453 November einfache Dispens presbiter et soluta (Reg. Pen. 4 174v - DN-Antragsnr. 37341); aus Schwäbisch Hall, in Rom 1453 Dezember 22 erste Tonsur und Akolyth, 1454 März 16 Subdiakon, 1454 April 6 Diakon, 1454 Juni 15 Priester, damals auch Pfarrer

73 RG 6 313, Nr. 3026; 383, Nr. 3750; RG 7 216, Nr. 1905; Wachter, Schematismus (wie Anm. 8), 123 Nr. 2436; Erik-Amulf Soder von Güldenstubbe, Die katholischen Pfarrer von Herzogenaurach. Ein Beitrag zur Kirchengeschichte, in: Heimatbuch der Stadt Herzogenaurach (Herzogenaurach 2. Aufl. 1979) 124; Suttner, Schematismus (wie Anm. 12), 67.

74 Suttner, Schematismus (wie Anm. 12), 26.

75 RG 9 Nr. 3140; Engel, Quellen (wie Anm. 3), 217 Nr. 1393; Theobald Freudenberger, Quellen zur Geschichte der Wallfahrt und des Augustinerchorherrenstifts Birklingen bei Iphofen (Mfr.) 1457-1546, in: Würzburger Diözesangeschichtsbll. 5 (1937) 147; im folgenden zitiert: Freudenberger, Birklingen. Wachter, Schematismus (wie Anm. 8), 519 Nr. 10466; Suttner, Schemarismus (wie Anm. 12), X.

76 RG 8 Nr. 1609; RG 9 Nr. 1790, 3150; Scherg, Franconica (wie Anm. 3), 1 58, Nr. 79, 61 Nr. 90; Engel, Urkundenregesten (wie Anm. 51), 269; Ebner, Bruderschaftswesen (wie Anm. 29), 293.

77 Suttner, Schematismus (wie Anm. 12), 17f. [zwei Pfarrkirchen in Berolzheim] 44.

78 Wachter, Schematismus (wie Anm. 8), 125 Nr. 2481; Bendeh, Diözesanmatrikel (wie Anm. 14), 7 Nr. 227 [Schlüsselfeld]. 
Kirnberg [Präsentation Benediktinerkloster Komburg], ab 1464 Pfarrer Großaltdorf. ${ }^{79}$ Christoph Fleischmann (Fleisman) Scholar Würzburger Diözese 1475 April einfache Dispens presbiter et soluta (Reg. Pen. $23243 v$ - DN-Antragsnr. 11677). Georg Fleischmann (Flaschman) Scholar Eichstätter Diözese 1480 Februar erste Dispens solurus et soluta (Reg. Pen. 29 193r - DN-Antragsnr. 14210).

Johann Vogel Würzburger Diözese Scholar 1480 November [gemeinsam mit seinem Bruder Konrad] erste, Priester 1494 Dezember erweiterte Dispens presbiter et soluta per fiat besaß eine Pfründe ohne Seelsorge (Reg. Pen. 30 126v, 44 380r - DN-Antragsnr. 14520, 14521, 22402). Johann Vogel 1444 Kanoniker und 1451 Scholaster von Neumünster [also solcher Vorgänger des Georg Hoeloch], gestorben 1456/58. Johann Vogel 1457 Studium Leipzig, Magister, 1471 Frühmesser bei St. Martin in Iphofen, 1478 Studium Wien, gestorben 1516 als Unterpfarrer in Herpf [Oberpfarrer aufgrund Inkorporation ein Stiftskanoniker zu Neumünster]. Konrad Vogel gestorben 1491 Juni 7 als Abt des Zisterzienserklosters Bronnbach. ${ }^{80}$

Michael Volckmar (Volclinari) Scholar Würzburger Diözese 1480 November erste Dispens presbiter et soluta (Reg. Pen. 30 126v - DN-Antragsnr. 14530). Michael Volckmar aus Rothenburg 1446 Studium Leipzig, 1450 dort baccalaureus artium, 1458 Pfarrverweser Insingen, 1460 Pfarrer Windelsbach, 1488 Kaplan von St. Leonhard bei Rothenburg, gestorben 1501, im Testament 1496 Stipendium 15 fl für Michael den Jüngeren, der 1513 Kaplan Kirchberg. ${ }^{81}$ Johann Volckmar (Falkmar) Kleriker Bamberger Diözese 1516 März erste und gleichzeitig erweiterte Dispens solutus et soluta mit Kommission an den Abt des Benediktinerklosters Mönchröden [bei Coburg] Würzburger Diözese, besaß eine Pfründe ohne Seelsorge (Reg. Pen. $60410 \mathrm{r}$ - DN-Antragsnr. 29821). ${ }^{82}$

Erasmus Volmar Würzburger Diözese Scholar 1495 September erste, Akolyth 1495 Oktober erweiterte Dispens presbiter et soluta per fiat, während zuvor auctoritate ordinaria dispensiert (Reg. Pen. 45 476r, 508v - DN-Antragsnr. 22474, 22817).

Johann Franck Scholar Würzburger Diözese 1463 Februar einfache Dispens presbiter et soluta (Reg. Pen. 11 306v - DN-Antragsnr. 4036); Kleriker 1466 Ewigvikar am Elisabethaltar im Nonnenkloster Kitzingen 3 Mark. Johann Franck von Oberbach Eichstätter Diözese Scholar 1469 März einfache, Priester 1470 Januar erweiterte Dispens presbiter et soluta per fiat, besaß eine einfache Pfründe (Reg. Pen. 17 165r, 18 261 - DN-Antragsnr. 7852, 8938). Johann Franck 1472 Frühmesser Großlangheim. Paul Franck Scholar Eichstätter Diözese 1470 Januar einfache Dispens presbiter et soluta (Reg. Pen. 18 237r - DN-Antragsnr. 8446). Leonhard Franck Scholar Würzburger Diözese 1483 März erste Dispens presbiter et soluta (Reg. Pen. 32 202r - DN-Antragsnr. 15618); 1492 Studium Basel, von 1512 bis zu seinem Tod 1537 Februar 11

79 RG 6 427, Nr. 4212; Engel, Quellen (wie Anm. 3), 184 Nr. 1154. Großaltdorf Bendel, Diözesanmatrikel (wie Anm. 14), 11 Nr. 438; Kirnberg: ebd., 9 Nr. 373. Die Pfarrei Kirnberg besaß jedoch seit spätestens 1441 Johann Jäger, der sie 1455 an Stephan Schmidt vertauschte: Borchardt, Rothenburg (wie Anm. 22), 579 Nr. 225, 583 Nr. 277.

80 Wendehorst, Neumünster (wie Anm. 14), 379; Holzapfeh Baunach (wie Anm. 53), 90 mit Anm. 498; Freudenberger, Birklingen (wie Anm. 75), 114; Weiß, Nordosten (wie Anm. 15), 235; Friedrich Merzbacher, Johann von Allendorf. Stiftsprobst von St. Burkard und bischöflicher Kanzler (1400-1496). Ein Lebensbild aus dem spätmittelalterlichen Würzburg (QFW [wie Anm. 3], 11, Würzburg 1955) 57; im folgenden zitiert: Merzbacher, Allendorf. Brigitte Schröder, Mainfränkische Klosterheraldik. Die wappenführenden Mönchsklöster und Chorherrenstifte im alten Bistum Würzburg (QFW [wie Anm. 3], 24, Würzburg 1971) 101.

81 Borchardt, Rothenburg (wie Anm. 22), 584 Nr. 290, 643.

82 Bendeh Diözesanmatrikel (wie Anm. 14), 29. 
Kaplan der Marienkapelle in Crailsheim. Andreas Franck Scholar Würzburger Diözese 1500 April erste Dispens presbiter et soluta (Reg. Pen. 48 848r - DN-Antragsnr. 24410). ${ }^{83}$

Peter Freytag Eichstätter Diözese 1450 Oktober einfache Dispens presbiter et soluta (Reg. Pen. 4 44r - DNAntragsnr. 35151). Peter Frit(d)ag Kleriker Mainzer Diözese, päpstlicher Familiar 1455 Pfarrkirchen St. Martin und St. Kilian Nierstein, 1457 Ewigvikarie in einem Kloster bei Oppenheim, Kapelle St. Peter Nierstein Diözese Mainz. ${ }^{84}$

Johann Gemelich Würzburger Diözese Scholar 1481 Dezember erste, Kleriker 1492 Februar erweiterte Dispens presbiter et soluta per fiat, Pfarrei Inferiori Espach [?] Diözese Mainz (Reg. Pen. 31 206v, 41 370v DN-Antragsnr. 15030, 20934). Johann Gemelich 1457 Präsenzmeister, 1471 Domvikar Würzburg. ${ }^{85}$

Die Brüder Johannes Georgii und Paul Johannis von Giech Scholaren Bamberger Diözese 1463 März einfache Dispens solutus et soluta (Reg. Pen. $11311 \mathrm{v}$ - DN-Antragsnr. 4089, 4090).

Johann Greul (Grewl) Akolyth Würzburger Diözese 1468 Mai einfache Dispens solutus et soluta, während zuvor Defekt verschwiegen (Reg. Pen. 16 187r - DN-Antragsnr. 7430); 1480 Frühmesser Möckenhausen Diözese Eichstätt [Präsentation Abr des Benediktinerklosters Plankstetten], ordiniert in Würzburg und in Stulpen [?] Diözese Meißen auf die Frühmesse in Erlbach Diözese Würzburg und die Landgrafen [von Thüringen?]. Nicht zu verwechseln Johann Greul geboren um 1470 in Egenhausen bei Schweinfurt, seit 1501 Pfarrer Ottakring bei Wien, als Johannes Menanus Ostrofrancus in Humanistenkreisen namhaft, Autor einer metrischen Kilianslegende. ${ }^{86}$

Nikolaus Habermann (Haverman) Scholar Würzburger Diözese 1519 Oktober und anwesend an der römischen Kurie 1519 Dezember erste Dispens solutus et soluta mit Kommission erst an Erzbischof von Mainz, dann an Bischof von San Leone in Rom (Reg. Pen. 65 400v, 413r - DN-Antragsnr. 30755, 30849); Domschulmeister und -vikar Würzburg 1539, Engelmesser Dettelbach $15400^{87}$

Georg Haindl Scholar Eichstätter Diözese 1481 September erste Dispens presbiter et soluta (Reg. Pen. 31 201r - DN-Antragsnr. 14905). Leonhard Heindl 1480 Kaplan im Heiliggeistspital zu Ingolstadt [Präsentation durch Stadt]. ${ }^{88}$

Johann Heidenreich (Heydenpreuch, Heidenreh) Bamberger Diözese Scholar 1510 Okrober erste, Kleriker 1524 Februar erweiterte Dispens presbiter et soluta, besaß eine Pfründe (Reg. Pen. 55 812r, 71 13r - DNAntragsnr. 28094, 32171); 1504 Studium Leipzig, 1509 Magister artium, als Nachfolger des 1511 Mai 13 verstorbenen Magister Erhard Königsdörfer Altarist und Kaplan am Katharinenaltar in St. Michael zu Hof,

83 RG 9 Nr. 3178; Sebastian Zeißner, Geschichte von Großlangheim, m. Unterstützung v. Georg Spath (Würzburg 1933) 41; im folgenden zitiert: Zeißner, Großlangheim; Weiß, Baseler Studenten, in: Würzburger Diözesangeschichtsbll. 16/17 (1955) 237.

84 RG 7270 , Nr. 2401.

85 Sebastian Zeißner, Dr. Kilian von Bibra, Dompropst von Würzburg (ca. 1426-1494), in: MainfrJb 2 (1950) 109; Fischer, Vikarien, in: Würzburger Diözesangeschichtsbll. 3 (1935) 17; Borchardt, Jahrtagslisten (wie Anm. 29), 166.

86 Suttner, Schematismus (wie Anm. 12), 32; Bendeh, Diözesanmatrikel (wie Anm. 14), 7 Nr. 262; Albin Franz Scherhaufer, Johannes Menanus Ostrofrancus Greul - ein vergessener Humanist des Mainlandes (Veröffentlichungen des HV und Stadtarch. Schweinfurt H. 5, Schweinfurt 1957) 8-32.

87 Bayerische Archivinventare H. 30: Die Archive des Landkreises Kitzingen, Teil 2: Die Stadtarchive. Bearb. v. Fritz Mägerkein, Walter Scherzer (München 1968) 28.

88 Suttner, Schematismus (wic Anm. 12), 38. 
1515 Priester, 1519 Kursor der Theologie in Leipzig, 1532 und 1536 in Hof, um 1547 verstorben; [derselbe?] genannt Prätor 1518 Frühmesser Reckendorf bei Baunach. ${ }^{89}$

Konrad Heynfogel Scholar Bamberger Diözese 1487 Dezember erste Dispens presbiter et soluta (Reg. Pen. 37311 r - DN-Antragsnr. 18317). Konrad Heinvogel von Nürnberg 1467 Studium Erfurt, 1490 Priester, gestorben 1517 in Nürnberg. ${ }^{90}$

Johann Helperger Scholar Eichstätter Diözese 1473 Februar erste und Mai erweiterte Dispens presbiter et soluta per fiat, besaß eine Pfründe (Reg. Pen. 21 174v, 194r - DN-Antragsnr. 10301, 10631).

Johann Hering (Herinch, Hernick) Kleriker Eichstätter Diözese 1473 September erweiterte Dispens diaconus et coniugata per fiat, Kanoniker zu Herrieden Diözese Eichstärt (Reg. Pen. 22 198v - DN-Antragsnr. 11118); Scholar 1464 September und 1465 August einfache Dispens, das erste Mal fälschlich diaconus et soluta (Reg. Pen. 13 277v, 12 159r - DN-Antragsnr. 5686, 5437); ordiniert in Naumburg auf den Georgsaltar in St. Wipert zu Erfurt, 1480 Pfarrer in Pfofeld Diözese Eichstätt [Präsentation Prior in Rebdorf]; kraft Erlaubnis, zu Kanonikat mit Präbende in Herrieden 6 Mark eine weitere Pfründe mit Seelsorge zu erlangen, 1480 zusätzlich Pfarrei St. Martin in Tallga [?] Diözese Salzburg mit $90 \mathrm{f} \mathrm{rh} .{ }^{91}$

Johann Herolt Kleriker Würzburger Diözese 1508 August einfache Dispens presbiter et soluta, während zuvor Defekt verschwiegen (Reg. Pen. 54 810r - DN-Antragsnr. 27526). Johann Herolt aus Zeil am Main 1484-1495 Studium Leipzig, 1494 Subdiakon in Merseburg, 1509 als Johann Herolt der Ältere Pfarrer Reinsberg bei Schwäbisch Hall. ${ }^{92}$

Wilhelm Heuberger (Hewberger) Priester Eichstätter Diözese 1468 März erweiterte Dispens solutus et monialis ordinis sancti Benedicti per fiat, Pfarrer St. Peter und Ulrich in Manching Diözese Augsburg (Reg. Pen. 16 199r - DN-Antragsnr. 7653). Heinrich Heuberger Priester Würzburger Diözese 1419 ungeachtet Dispens Ewigvikarie der Pfarrkirche St. Johannis in Ellrichshausen Diözese Würzburg [Präsentation Dominikanerinnenkloster Rothenburg]. Willibald Heuberger 1461 Pfarrer Laibstadt 8 Mark und Domvikar Eichstätr 8 Mark, 1480 nicht residierender Pfarrer Laibstadt [Präsentation Dompropst Eichstärt]. ${ }^{93}$

Johann Hoffmann Scholar Würzburger Diözese 1470 Januar erste Dispens presbiter et soluta (Reg. Pen. 18 237r - DN-Antragsnr. 8447). Johann Hoffmann Scholar Würzburger Diözese 1475 Mai erste Dispens presbiter et soluta (Reg. Pen. 23 246v - DN-Antragsnr. 11815). Johann Hoffmann verschiedene Personen: 1446 Studium Wien, 1460-1466 Domvikar Würzburg, 1470/71 Pfarrer Eibelstadt. 1476 Kaplan Leofels. Kleriker 1486 Erste Bitten König Maximilians auf Pfarrer Iphofen. 1496 Pfarrer Erlenbach am Main. Aus Gerolzhofen, 1501 Abschrift eines Traktats. Bis 1495 Pfarrverweser Mürsbach, in der Priesterbruderschaft Baunach irrig als Priester eingetragen und daher wieder gestrichen, 1501 Pfarrverweser Ebern, 1504 bis 1511 Pfarrer Ebern. 1515 Vikar St. Burkhard zu Würzburg, 1527 [!] Domvikar Würzburg. ${ }^{94}$ Johann

89 Lehnes, Baunachgrund (wie Anm. 32), 193; Wachter, Schematismus (wie Anm. 8), 192 Nr. 3924f.; Kist, Matrikel (wie Anm. 8), 167 Nr. 2502; von Guttenberg, Wendehorst, Bamberg (wie Anm. 13), $242 \mathrm{f}$.

90 Kist, Matrikel (wie Anm. 8), 170 Nr. 2553.

91 Suttner, Schematismus (wie Anm. 12), 20; Scherg, Franconica (wie Anm. 3), $3113 f$., Nr. $747 f$.

32 Weiß, Weihekandidaten (wie Anm. 46), 163.

93 RG 8 Nr. 5924; Engeh Quellen (wie Anm. 3), 156 Nr. 972; Borchardt, Rothenburg (wie Anm. 22), 187; Suttner, Schematismus (wie Anm. 12), 28.

${ }^{4}$ Lehnes, Baunachgrund (wie Anm. 32), 40, 56, 66, 195; Cornelius Will Jubiläum herrn Johanns graven vnd herren zu Rieneck, so er gehalten 1528 [!] d. 12. Nov., in: Arch. des HV von Unterfranken 19/2 (1867) 215; im folgenden zitiert: Will, Jubiläum; Michael Wieland, Historische Darstellung des Stiftes St. Burkard zu Würzburg, in: Arch, des HV von Unterfranken 15/2-3 (1861) 71; Weiß, Erste Bitten (wie Anm. 34), 114 Nr. 70; Holzapfel, Baunach (wie Anm. 53), 28 Z 53; 49, 66; Borchardt, Jahrtagslisten (wie Anm. 29), 177 Anm.; Johann Baptist Kestler, Beiträge zur Geschichte der Stadt Eibelstadt, in: Arch. des HV von 
Hoffmann von Hilpoitstein Scholar Eichstätter Diözese 1500 April erste Dispens in adulterio procreatus (Reg. Pen. 48 849r - DN-Antragsnr. 24428).

Johann Hopf Scholar Würzburger Diözese 1464 Januar einfache Dispens solutus et soluta (Reg. Pen. 13 243r - DN-Antragsnr. 4623). Johann Hopf 1510 bis vermutlich 1518 Schloßkaplan Rieneck. ${ }^{95}$

Konrad Hubner Scholar Eichstätter Diözese 1451 Oktober erste Dispens monachus et soluta (Reg. Pen. 4 53v - DN-Antragsnr. 35927); Priester 1462 Pfarrer Mitteleschenbach Diözese Eichstätt 24 Kammerdukaten. ${ }^{96}$

Johann Hummel Scholar Würzburger Diözese 1450 August bzw. September einfache Dispens solutus bzw. presbiter et soluta (Reg. Pen. 4 42v, 43r - DN-Antragsnr. 35030, 35064); Prozeß 1461 um Heiligkreuzaltar in Pfarrkirche Freiburg Diözese Konstanz 4 Mark. Jordan Hummel 1415 Kaplan des Abtes von Neustadt am Main. ${ }^{\text {? }}$

Johann Hunckel (alias Finckel) von Herrieden Scholar oder Kleriker Eichstätter Diözese 1512 Mai erste Dispens solutus et soluta (Reg. Pen. 57 27r - DN-Antragsnr. 28814); Priester Eichstätter Diözese, 15431545 Früh- und Mitrelmesser Herzogenaurach. ${ }^{98}$

Johann Lamerpach Kleriker Bamberger Diözese 1500 Juni erweiterte Dispens presbiter et soluta per fiat für drei Pfründen, während zuvor auctoritate ordinaria dispensiert (Reg. Pen. 48 897v-DN-Antragsnr. 24780).

Heinrich Lange Scholar Bamberger Diözese 1491 Juni erste Dispens solutus et soluta (Reg. Pen. 40 508v DN-Antragsnr. 20195). Heinrich Lang von Forchheim 1521 Studium Erfurt, Frühmesser Stadtsteinach bis zu seinem Tod $1530 .^{99}$

Berthold Lecter Priester Würzburger Diözese 1467 Juni erweiterte Dispens presbiter et soluta, besaß eine Pfründe ohne Seelsorge (Reg. Pen. 15 232r - DN-Antragsnr. 7047).

Die Brüder Johann und Jodokus Lemlein Scholaren Bamberger Diözese 1493 Mai erste Dispens subdiaconus et soluta (Reg. Pen. 42 276v - DN-Antragsnr. 21298f.). Johann Lemlein Kleriker Würzburger Diözese 1480/81 Prozeß um Pfarrei Remlingen 6 Mark; 1489 Jahrespension $29 \mathrm{fl}$ th vom Stiftskapitel Wertheim. Zwei Personen Johann Lemlein, einer Chorherr von St. Jakob und der andere Chorherr von St. Stephan zu Bamberg, beide der Zeit nach mögliche Väter. ${ }^{100}$

Die Brüder Erhard und Wilhelm Lesch Scholaren Würzburger Diözese 1449 April einfache Dispens coniugatus et soluta (Reg. Pen. 4 14rv - DN-Antragsnr. 33401, 33402). Eberhard Lesch Propst auf dem Marienberg, 1424 Abr des Benediktinerklosters St. Burkhard in Würzburg, 1436 Oktober 21 gestorben. ${ }^{101}$

Unterfranken 5/1 (1838) 37; Remling, Bruderschaften (wie Anm. 27), 179; Hans Thurm, Die Handschriften des 15. Jahrhunderts aus der Benediktinerabtei St. Stephan zu Würzburg, in: Würzburger Diözesangeschichtsbll. 47 (1985) 63.

${ }^{25}$ Kaltenbach, Die Grafen von Loon und Ryneck, in: Arch. des HV von Unterfranken 19/3 (1868) 121; Wieland, Rieneck (wie Anm. 65), 134, 316, 318.

26 RG 8 Nr. 714.

97 RG 8 Nr. 3572; Johann Adolph Kraus, Urkundliche Nachrichten über das Kloster Einsiedel im Spessart, in: Arch. des HV von Unterfranken $9 / 3(1848) 126,135$.

98 Wachter, Schematismus (wie Anm. 8), 124 Nr. 2462.

99 Kist, Matrikel (wie Anm. 8), 249 Nr. 3791.

100 Engel, Quellen (wie Anm. 3), 250 Nr. 1635; 252 Nr. 1649; 1489 Januar 24; S 897 238v; Kist, Matrikel (wie Anm. 8), 255 Nr. $3883 f$.

101 Die Würzburger Inschriften bis 1525. Auf der Grundlage des Nachlasses von Theodor Kramer unter Mitarbeit v. Franz Xaver Herrmann bearb. v. Karl Borchardt (Die Deutschen Inschriften 27, Wiesbaden 1988) 105f. Nr. 210. 
Adam Linck, wohl aus Schwabach ${ }^{102}$, Diakon Eichstätter Diözese 1470 November erweiterte Dispens presbiter et soluta, besaß die Levitrie im Dom zu Eichstätt 6 Mark (Reg. Pen. 18 273r - DN-Antragsnr. 9037).

Peter Lutifiguli Subdiakon Würzburger Diözese 1477 Januar erste Dispens solutus et soluta (Reg. Pen. 25 173r - DN-Antragsnr. 12864). Erwin Lutifiguli 1392 Vikar im Stift Aschaffenburg. ${ }^{103}$

Wolfgang Marschalk Bamberger Diözese Scholar 1454 Dezember einfache, Priester 1466 März erweiterte Dispens solutus et soluta, besaß Pfarrei Ebensfeld [bei Staffelstein, Patronat der Älreste Marschalk von Ebneth] 5 Mark (Reg. Pen. 4 224r, 14 330r - DN-Antragsnr. 37752, 6393); 1466 Erlaubnis für zusätzliche Pfründe. Wolfram [!] Marschalk 1470 Pfarrer Ebensfeld, 1489-1505 Pfarrer Burgkunstadr [Verleihung durch Bischof von Bamberg], zudem 1489 Frühmesser Altenkunstadt. ${ }^{104}$ Johann Marschalk Priester Eichstätter Diözese 1465 November und 1468 Dezember erweiterte Dispens diaconus et soluta, beim zweiten Mal per fiat, besaß zunächst ein Kanonikat in St. Marien zu Eichstätr 4 Mark, dann zusätzlich ein beneficium simplex 5 Mark. Johann Marschalk von beiden Eltern aus ritterlichem Geschlecht, im 19. Lebensjahr 1463 Kanoniker und Scholaster der Alten Kapelle zu Regensburg, im Studium, dilectus des Herzogs Albrecht von Bayern 1465 Domkanonikat zu Bamberg mit Reservation von Präbende und Exspektative auf Regensburg. ${ }^{105}$

Georg Michler Priester Würzburger Diözese 1466 Januar einfache Dispens solutus et soluta, während zuvor Defekt verschwiegen (Reg. Pen. 14 244r - DN-Antragsnr. 5815). Johann Michler 1461 Pfarrer Wiesenfeld. ${ }^{106}$

Sixt Moll Scholar Eichstätter Diözese 1469 September erste Dispens presbiter et soluta (Reg. Pen. 17 177r DN-Antragsnr. 8180); 1480 Cooperator der Pfarrei Gaimersheim Diözese Eichstätt, ordiniert in Augsburg auf sein Privatvermögen. ${ }^{107}$

Johann Munch Würzburger Diözese Scholar 1471 März erste, Kleriker 1485 Januar erweiterte Dispens presbiter et soluta per fiat, besaß eine Vikarie ohne Seelsorge in Gerolzhofen (Reg. Pen. 19 47r, 34 253v DN-Antragsnr. 9159, 16341); als Diakon Würzburger Diözese und Pfarrer Schmalfelden 1491 Aufschub der Priesterweihe erst um ein weiteres Jahr, dann um zwei weitere Jahre. ${ }^{108}$ Martin Munch Scholar Würzburger Diözese 1476 Juni erste Dispens presbiter et soluta (Reg. Pen. 24 218r - DN-Antragsnr. 12634); Priester 1485 Pfarrer Sommerhausen 3 Mark, Prozeß um Pfarrei Ettleben 7 Mark, 1486 Prozeß um Domvikarie Würzburg 4 Mark; wegen Verwundung eines anderen Priesters 1492 als Pfarrer zu Ettleben

102 Oder Windsheim: Borchardt Rothenburg (wie Anm. 22), 294, 504, 549. In Schwabach 1480 Pfarrer Peter Linck: Suttner, Schematismus (wie Anm. 12), 64.

${ }_{103}$ August Amrbein, Beiträge zur Geschichte des Archidiakonates Aschaffenburg und seiner Landkapitel, in: Arch. des HV von Unterfranken 27 (1884) 147.

104 RG 9 Nr. 6578; Kist, Matrikel (wie Anm. 8), 276 Nr. 4180; von Guttenberg, Wendehorst, Bamberg (wie Anm. 13), 158, 167, 169.

105 RG 8 Nr. 3228; RG 9 Nr. 3547.

106 Alexander Kaufmann, Kleine Beiträge zur Geschichts- und Sagenforschung im Frankenlande, in: Arch. des HV von Unterfranken 26 (1886) 410.

107 Suttner, Schematismus (wie Anm. 12), 35.

108 1491 Oktober 10: ASV S 944 54v; 1491 Oktober 17: S 944 214r; Frühmesse, Spitalvikarie, Engelund Mittelmesse durch Bischof von Würzburg, Messe der Bruderschaft in Gerolzhofen: Bendeh, Diözesanmatrikel (wie Anm. 14), 4 Nr. 142, 25 Nr. 997. 
und Obernbreit sowie Ewigvikar im Stift Haug zugunsten des Nikolaus von Gnodstadt, Familiar des Bischofs Johann Anton von Alessandria, abgesetzt. ${ }^{109}$

Rudolf von Münkheim Scholar Würzburger Diözese 1487 Oktober erste Dispens solurus et soluta (Reg. Pen. 37 308r - DN-Antragsnr. 18265).

Johann Murrer alias Holderlein Diakon Eichstätter Diözese 1473 Oktober erweiterte Dispens presbiter et soluta per fiat, besaß Chorherrnpfründe 6 Mark (Reg. Pen. 22 200r - DN-Antragsnr. 11129).

Georg Mutzing Scholar Würzburger Diözese 1498 April erste Dispens presbiter et soluta (Reg. Pen. 46 430r - DN-Antragsnr. 23153). Johann Mutzing Priester Mainzer Diözese zwischen 1490 und 1500 erster Vikar des Thomasbenefiziums an der Pfarrkirche Haßfurt. ${ }^{110}$

Kilian (Beltanus) Ni(e)bling Würzburger Diözese Scholar 1482 April erste, Diakon 1496 März erweiterte Dispens clericus / presbiter et soluta, besaß Pfründe ohne Seelsorge in der Kirche zu Wyden [?] (Reg. Pen. 31 214v, 45 515v - DN-Antragsnr. 15199, 22849). Johann Nibeling Kleriker Würzburger Diözese anwesend an der römischen Kurie 1465 Exspektative in forma pauperum auf Würzburg, 1468 Frühmesse Euerhausen 4 Mark, Domvikarie St. Jakob und Eulogius in Würzburg 4 Mark, 1469 Pfarrei Mosbach 8 Mark, alles Würzburger Diözese, gestorben 1486 vor September 28. ${ }^{111}$ Johann Nibling geboren 1463 in Volkach, 1485 Studium Ingolstadt, artium liberalium determinator, baccalaureus theologie, Zisterzienser, Prior in Ebrach um 1500 bis 1524, dann bis Tod 1526 subprocurator des Ebracher Hofes in Nürnberg. ${ }^{112}$

Johann Obhammer Scholar Bamberger Diözese 1497 November erste Dispens solutus et soluta (Reg. Pen. 46415 r - DN-Antragsnr. 22977). Johann Odhammer (Otthammer) [!] 1519 Ewigvikar Redwitz, gestorben $1527 .^{113}$

Johann Ochs Scholar Eichstätter Diözese 1483 April erste Dispens solutus et soluta (Reg. Pen. 32 205r DN-Antragsnr. 15746). Johann Ochs aus Gunzendorf 1480 Stiftskustos in Herrieden. ${ }^{114}$

Balthasar Oser Scholar Würzburger Diözese 1491 März erste Dispens presbiter et soluta (Reg. Pen. 40 497v - DN-Antragsnr. 20033). Martin Öser, Sohn des alten pfalzgräflichen Schultheißen zu Möckmühl, 1498 Nachfolger des verstorbenen Propstes des Stifrs Möckmühl. ${ }^{115}$

Kilian Rab Scholar Bamberger Diözese 1465 Januar einfache Dispens presbiter et soluta (Reg. Pen. 12 143r DN-Antragsnr. 5068); niedere Weihen 1465 April 13 in Bamberg. ${ }^{116}$

109 1485 April 16: ASV S 845 243v; 1485 April 26: S 845 198v-199r; 1486 Mai 12: S 857 277v; 1492 Januar 27: $S 951$ 5rv.

110 Eugen Kainz, Ein Register der Pfarrei Haßfurt aus dem Jahre 1612, in: Würzburger Diözesangeschichtsbll. 7 (1939) 43.

111 RG 9 Nr. 3644; 1486 September 28: ASV S 862 175r.

112 Wilhelm Engeh Varia Eberacensia aus dem ${ }_{n}$ Hausbuch" des Priors Johann Nibling (1489-1521), in: Würzburger Diözesangeschichtsbll. 11/12 (1949/50) 213-216; Johannes Kist, Ebracher Zisterzienser und ihr Universitätsstudium im Mittelalter, in: Würzburger Diözesangeschichtsbll. 14/15 (1952/53) 346; Jaeger, Verzeichnis, Cistercienser-Chronik 14 (1903) 48; Die Inschriften des Landkreises Bamberg bis 1650 . Bearb. v. Rudolf Maria Kloos (Die Deutschen Inschriften 18, München 1980) XV; Hans Thurn. Die Ebracher Handschriften in der Universitätsbibliothek Würzburg, in: Würzburger Diözesangeschichtsbll. 31 (1969) 7.

113 Kist, Matrikel (wie Anm. 8), 307 Nr. 4655; von Guttenberg, Wendehorst, Bamberg (wie Anm. 13), 170.

114 Sutmer, Schematismus (wie Anm. 12), 60.

115 DAW Klöster und Stifte, Möckmühl Nr. 4: Ausf. Pap. Heidelberg 1498 Dezember 3, Pfalzgraf Philipp an Bischof Lorenz von Würzburg mit Bitte um Bestätigung.

116 Kist, Matrikel (wie Anm. 8), 311 Nr. 4722. 
Balthasar Rederer Priester Eichstätter Diözese und licentiatus in decretis 1493 November erweiterte Dispens presbiter et soluta per fiat, besaß Pfarrei Oberstotzingen [Diözese Augsburg?] (Reg. Pen. $43421 \mathrm{r}$ - DNAntragsnr. 21936).

Die Brüder Heinrich der Ältere, Johann und Heinrich der Jüngere Reich von Burgkunstadt 1482 Juli erste Dispens presbiter et soluta (Reg. Pen. 31 218v - DN-Antragsnr. 15321-23). Heinrich verstarb 1533 als Pfarrer in Pautzfeld [Diözese Bamberg, Präsentation durch Stift Forchheim]. Johann 1489 Kleriker und Zeuge, nach Resignation des Heinrich Schultheiß 1496 durch Alexander VI. Inhaber der Nikolauskapelle bzw. Frühmesser Reckendorf [Filia der Pfarrkirche Baunach] (belegt 1499 und 1500). ${ }^{117}$

Peter Renck Scholar Würzburger Diözese 1482 Januar erste Dispens presbiter et soluta (Reg. Pen. 31 209v DN-Antragsnr. 15089). Johann Renck aus Karlstadt Kleriker Würzburger Diözese, dilectus Markgraf Friedrichs II. von Brandenburg, auf dessen Bitten 1465 Juni 1 Exspektativen auf Domkapitel und Stift Haug zu Würzburg, 1465/66 Studium Leipzig, 1469 Notar, 1477 Propst des Stiftes Rasdorf, unter Verdrängung des Heinrich Fleischmann auf Betreiben des Dr. Dietrich Morung seir 1489 Stiftskantor von Neumünster, bezeugt bis 1502 , gestorben Juni $20 .^{118}$

Johann von Romrod (Raumenrode) Kleriker Würzburger Diözese 1455 Januar erweiterte Dispens solutus et soluta per fiat, während zuvor auctoritate ordinaria dispensiert (Reg. Pen. $4227 \mathrm{v}$ - DN-Antragsnr. 37799).

Johann Rorer Scholar Eichstätter Diözese, anwesend an der tömischen Kurie 1522 März erste Dispens presbiter et soluta (Reg. Pen. 61 1v - DN-Antragsnr. 31468). 1480 Konrad Rorer Burgkaplan Sulzbürg. Ulrich Rorer Pfarrer Klapfenberg. Johann Rorer seit mindestens 1463 bis wenigstens 1480 Altarist am Hieronymusaltar der Pfarrkirche in Neumarkt, alles Diözese Eichstätt. ${ }^{119}$

Die Brüder Martin und Johann Rosa Scholar und Kleriker Bamberger Diözese 1471 März erste Dispens presbiter et soluta, während Johann zuvor Defekt verschwiegen (Reg. Pen. 19 47v-DN-Antragsnr. 09169f.). Johann Rosa Kleriker Bamberger Diözese 1477 Oktober erste Dispens presbiter et soluta, während zuvor Defekt verschwiegen (Reg. Pen. 26 219r - DN-Antragsnr. 13249). Johann Rosa von Bamberg, doctor decretorum, Professor für Kirchenrecht in Ingolstadt bis etwa $1510 .{ }^{120}$ Die Brüder Johann und Martin Rosz Scholaren Eichstätter Diözese 1479 Juni erste Dispens presbiter et soluta (Reg. Pen. 28 205v, 206r - DNAntragsnr. 13907f.). Johann Rose 1504 Notar in Schweinfurt. ${ }^{121}$

Veir Rot (Ret) Scholar Bamberger Diözese 1484 November erste Dispens salutus et soluta (Reg. Pen. 34 263r - DN-Antragsnr. 16442); aus Nürnberg, 1477 Studium Heidelberg, möglicherweise 1492 Vikar in Nürnberg. ${ }^{122}$

Johann Petri von Rotenhan (Rotheban?) Kleriker Würzburger Diözese 1468 April einfache Dispens solutus et soluta (Reg. Pen. 16 183r - DN-Antragsnr. 7285). Möglicher Vater Peter von Rotenhan zu Lichtenstein, Sohn des Albrecht, geboren 1427, gestorben 1479, oder der ältere Peter, Sohn des Georg von Rotenhan. ${ }^{23}$

117 Wachter, Schematismus (wie Anm. 8), 384 Nr. 7882f.; Kist, Matrikel (wie Anm. 8), 322 Nr. 4858; 1496 August 29: ASV L 994 27r-28r; von Guttenberg, Wendehorst, Bamberg (wie Anm. 13), 108 [130 keine Frühmesse in Reckendorf].

118 Wendehorst, Neumünster (wie Anm. 14), 435.

119 Suttner, Schematismus (wie Anm. 12), 31, 51, 53.

120 Kist, Matrikel (wie Anm. 8), 333 Nr. 5053.

121 Müller, Mellrichstadt, in: Franconia Sacra (1901) 191.

122 Kist, Matrikel (wie Anm. 8), 335f. Nr. 5095, 5097.

123 Gottfried Frhr. $\nu$. Rotenhan, Die Rotenhan. Genealogie einer fränkischen Familie von 1229 bis zum Dreißigjährigen Krieg (Veröffentlichungen der Ges. für fränkische Gesch. IX/34, Neustadt/Aisch 1985) 166-172 Nr. 703; 156 Nr. 673. 
Johann Rowt Scholar Würzburger Diözese 1472 August einfache Dispens solutus et soluta (Reg. Pen. 21 168v - DN-Antragsnr. 10158). Johann Rod(t) Kleriker Würzburger Diözese 1486 Dispens solutus et soluta für alle Weihen und Benefizien, als Familiar des Skriptors Ferdinandus de Ponzetti 1487 zusätzlich Dispens für zwei inkompatible Benefizien; 1500 in Rom, bis 1523 und 1526 bis 1527 Pfarrer Königshofen, 1527 Domvikar Würzburg. ${ }^{124}$ Wolfgang Pangratii Rott Kleriker Eichstätter Diözese 1507 Oktober einfache Dispens presbiter et coniugata (Reg. Pen. $53747 \mathrm{v}-$ DN-Antragsnr. 26991).

Wolfgang Sanctart (Santhart) Scholar Würzburger Diözese 1484 Dezember erste Dispens presbiter [secularis] et soluta (Reg. Pen. 34 265v - DN-Antragsnr. 16497); 1485 Oktober 10 Erlaubnis zum Empfang der niederen Weihen an der römischen Kurie. ${ }^{125}$

Georg Scharffenstein Scholar Würzburger Diözese 1510 Juni erste Dispens presbiter et soluta mit Kommission an Bischof von Mylopotamos, während zuvor Defekt verschwiegen (Reg. Pen. $55801 v$ - DNAntragsnr. 27977). Johann Scharffenstein Priester Würzburger Diözese 1511 Mai erste Dispens presbiter et soluta mit Kommission an Offizial von Würzburg, während zuvor Defekt verschwiegen (Reg. Pen. 56 824v - DN-Antragsnr. 28304); 1514-1522 Mittelmesser Großlangheim. ${ }^{126}$

Johann Schelhorn alias Gornn von Radelspurch Scholar Würzburger Diözese 1519 September erste Dispens coniugatus et soluta (Reg. Pen. 65 396v - DN-Antragsnr. 30721). Johann Schelhorn 1545 Kanoniker, 1550 Kapicular im Stift Aschaffenburg. ${ }^{127}$

Wolfgang Schicker Scholar Würzburger Diözese anwesend an der römischen Kurie 1512 Oktober erste Dispens solutus et soluta (Reg. Pen. 57 48r - DN-Antragsnr. 29021). Johann Schicker 1482 Studium Leipzig, 1486 Mai 20 Priester in Merseburg. ${ }^{128}$

Johann Schilling Scholar Würzburger Diözese 1474 März einfache Dispens solutus et soluta (Reg. Pen. 22 187r - DN-Antragsnr. 10881); 1476 Pfarrer Stöckenburg. ${ }^{129}$

Die Brüder Johann und Gangolf Schlatzawer Scholaren Würzburger Diözese 1500 April erste Dispens presbiter et coniugata (Reg. Pen. 48 850r - DN-Antragsnr. 24439f.). Konrad Schlatzhauer genannt Teufel 1495 präsentiert auf Egidiusvikarie von Neumünster zu Würzburg, 1506 vertauscht mit Frühmesse Volkach, 1516-1528 wieder Egidiusvikarie Neumünster, daneben 1520 Frühmesse Fladungen, 1526 Pfarrer Sondheim vor der Rhön, 1523 und um 1530 jeweils eine Vikarie in Mellrichstadt. ${ }^{130}$

Johann Schodlein Priester Eichstätter Diözese 1465 September erweiterte Dispens presbiter et soluta per fiat besaß eine Pfründe ohne Seelsorge (Reg. Pen. 13 302v - DN-Antragsnr. 5745).

Christoph Scholl (Schel) Scholar Bamberger Diözese 1500 Dezember erste Dispens presbiter et soluta (Reg. Pen. 49 695r - DN-Antragsnr. 25129); aus Bamberg, 1509 Studium Leipzig, Pfarrer Unterleinleiter [Präsentation durch Niederadel], dann 1531 Pfarrvikar Gößweinstein [dem Archidiakonat Hollfeld inkorporiert, verliehen durch Bischof von Bamberg], dann 1541 Frühmesser Eggolsheim, gestorben 1552 Januar

1241486 Oktober 24: S 863 28r; 1487 Juli 3: S 875 269r; Will, Jubiläum (wie Anm. 94), 215; Wilhelm Engeh Die Rats-Chronik der Stadt Würzburg (XV. und XVI. Jahrhundert) (QFW [wie Anm. 3] 2, Würzburg 1950) 79; ders., Würzburger in spätmittelalterlichen Bruderschaften der Stadt Rom, in: MainfrJb 2 (1950) 161; Weiß, Nordosten (wie Anm. 15), 238f.

125 ASV S $851241 \mathrm{r}$.

126 Zeißner, Großlangheim (wie Anm. 83), 42; Remling, Bruderschaften (wie Anm. 27), 351.

127 August Amrhein, Die Prälaten und Canoniker des ehemaligen Collegiatstiftes St. Peter und Alexander zu Aschaffenburg, in: Arch. des HV von Unterfranken 26 (1882) 213.

128 Weiß, Weihekandidaten (wie Anm. 46), 157; Holzapfel, Baunach (wie Anm. 53), 92.

129 Remling, Bruderschaften (wie Anm. 27), 179.

130 Wendehorst, Neumünster (wie Anm. 14), 700. 
30. Georg Scholl aus Gößweinstein erhielv 1539 Januar 10 Dispens super defectu natalium, später Pfarrer Eggolsheim, verstarb vor $1569 .^{131}$

Johann Schreck Scholar Würzburger Diözese 1457 August einfache Dispens presbiter et soluta (Reg. Pen. 6 110v - DN-Antragsnr. 1183). Konrad Schreck Studium 1414 Wien und 1425 Heidelberg, Pfarrer Gattenhofen [Präsentation Stadt Rothenburg] 1425 bis zu seinem Tod 1436, 1427 Pfarrer Sulzdorf, Vikar Creglingen, hatte einen Sohn Konrad. ${ }^{132}$

Friedrich Schrot Priester Eichstätter Diözese 1471 Oktober erweiterte Dispens presbiter et soluta per fiat, besaß eine Pfründe ohne Seelsorge (Reg. Pen. 20 245v - DN-Antragsnr. 10028); 1480 Inhaber der oberen Pfarrei in Walting bei Heideck [Präsentation durch Pankraz von Seckendorf], geweiht in Eichstätt und Freising auf eine Vikarie im Neuen Kolleg zu Spalt. ${ }^{133}$

Sigismund Seckendorffer Scholar Würzburger Diözese 1475 November erste Dispens solutus et soluta (Reg. Pen. 24 206r - DN-Antragsnr. 12310). Sigismund von Jochsberg Ewigvikar am Altar St. Johann Baptista in der Herrgottskapelle bei der Stadt Creglingen Diözese Würzburg mit Dispens 1488 Erlaubnis, sich an der römischen Kurie bis zum Priester weihen zu lassen; 1508 Kaplan zu Creglingen. Sigismund von Seckendorf zu Jochsberg, geboren 1486 August 9, 1546 Frühmesser Hallerndorf, 1547 Domvikar Bamberg, 1548 Studium Leipzig, zuletzt belegt 1549 Februar $23 .{ }^{134}$

Wilhelm Seehofer (Schofer) Scholar Würzburger Diözese 1466 Mai einfache Dispens presbiter et soluta (Reg. Pen. 14 254v - DN-Antragsnr. 6050); Wilhelm Seehofer aus ratsfähiger Familie in Rothenburg, Pfarrer Gattenhofen seit 1445 bis vor 1446, Kaplan am Andreasaltar in der Jakobskirche zu Rothenburg von nach 1459 bis zum Tode $1473 .{ }^{135}$

Konrad Seidenschwanz Würzburger Diözese Scholar 1450 April einfache, Kleriker 1454 Januar erweiterte Dispens solutus et soluta, besaß eine Pfründe (Reg. Pen. 4 33v, 149v - DN-Antragsnr. 34306, 37201); Kleriker Bamberger Diözese [!] 1455 Mai 29 Erlaubnis zum Empfang der Weihen in Rom. ${ }^{136}$

Johann Sichart Scholar Bamberger Diözese 1501 April erste Dispens presbiter et coniugata (Reg. Pen. 49 707 - DN-Antragsnr. 25303); möglicher gleichnamiger Vater seit 1497 Stiftskanoniker zu St. Stephan in Bamberg, gestorben 1504 vor März 11.137

Konrad Speret Scholar Würzburger Diözese 1459 September einfache Dispens (Reg. Pen. $7323 v$ - DNAntragsnr. 1922). Konrad Sporer Diakon und Pfarrer Mendhausen Diözese Würzburg 1464 Erlaubnis zum Aufschieben der Priesterweihe bis zum nächsten Termin. ${ }^{138}$

131 Kist, Matrikel (wie Anm. 8), 351 Nr. 5324; Wachter, Schematismus (wie Anm. 8), 422 Nr. 8651, 8653; von Guttenberg, Wendehorst, Bamberg (wie Anm. 13), 123, 129, 122 [zwei Frühmessen in Eggolsheim].

${ }_{132}$ Engel, Quellen (wie Anm. 3), 120 Nr. 731; Borchardt, Rothenburg (wie Anm. 22), 575 Nr. 183; Paul Schattenmann, Rothenburger Studenten auf der Universität Wien 1377-1450, in: Linde 38 (1956) 50 mit Anm. 4.

133 Suttner, Schematismus (wie Anm. 12), 81.

1341488 März 24: ASV S 883 76rv; Gerhard Rechter, Die Seckendorff. Quellen und Studien zur Genealogie und Besitzgeschichte, Bd. 1: Stammlinie mit den Linien Jochsberg und Rinhofen (Veröffentlichungen der Ges. für fränkische Gesch. IX/36, Neustadt/Aisch 1987) 159 Nr. V/1.

135 Borchardt, Rothenburg (wie Anm. 22), 579 Nr. 234. Vgl. Wilhelm Schofer von Nürnberg, niedere Weihen 1437 Mai 25 in Bamberg: Kist, Matrikel (wie Anm. 8), 366 Nr. 5567.

136 RG 7 47, Nr. 415.

137 Wachter, Schematismus (wie Anm. 8), 472 Nr. 9553; Kist, Matrikel (wie Anm. 8), 386 Nr. 5879.

138 RG 9 Nr. 935. 
Leonhard Spet Scholar Eichstätter Diözese 1469 April einfache Dispens solutus et soluta (Reg. Pen. 17 168r - DN-Antragsnr. 7933).

Johann Stang von Weinsberg Kleriker Würzburger Diözese 1480 Juni erste Dispens solutus et soluta (Reg. Pen. 29 299r - DN-Antragsnr. 14368). Johann Stang von Ochsenfurt 1480 Notar in Würzburg. ${ }^{139}$

Jakob Starck Scholar Würzburger Diözese 1476 Januar erste Dispens solutus et coniugata (Reg. Pen. 24 $211 v$ - DN-Antragsnr. 12450). Jakob Starck aus Rittershausen bei Ochsenfurt 1436/37 Studium Heidelberg, 1449 Domvikar Würzburg und Einnehmer des Datz [bischöfliche Steuer], 1450 Pfarrer Ulsenheim und Kanoniker Liebfrauenstift Trier, 1452-1458 Kanoniker von Neumünster zu Würzburg. ${ }^{140}$

Die Brüder Wolfgang und Wendelin Steger Scholaren Würzburger Diözese 1500 September erste Dispens presbiter et soluta (Reg. Pen. $49677 \mathrm{v}$ - DN-Antragsnr. 24867f.). Martin Steger, gestorben vor 1476 März 10, und Peter Steger, beide Vikare Heilbronn. ${ }^{141}$

Die Brüder Kilian und Wilhelm Stein (Stewen) Scholaren Würzburger Diözese 1468 Juli einfache Dispens solutus et soluta (Reg. Pen. 16 188v - DN-Antragsnr. 7461f.); Kilian Stein Kleriker 1478 Exspektative auf St. Burkhard zu Würzburg, Familiar des Kardinals Francesco Todeschini-Piccolomini 1485 Pfarrer Langendorf Diözese Würzburg, Erlaubnis, sich ein Jahr lang nicht zum Priester weihen zu lassen (1486 um ein Jahr verlängert), Kanonikat mit Präbende Münstermaifeld Diözese Trier 6 Mark, in Rom 1487 Weihe zum Subdiakon und Priester, Pfarrei Horitsteynbach [?] Diözese Bamberg 8 Mark, aufgrund Exspektative 1488 Ewigvikarie am Fronleichnams- und Marienaltar im Neumünster zu Würzburg und wegen Abwesenheit von der römischen Kurie Verlängerung der Frist zum Empfang der Priesterweihe, 1489 Resignation einer Ewigvikarie bei St. Burkhard außerhalb der Mauern zu Würzburg. Dr. iur. Peter von Stein 1478 Oberpfarrer Herbolzheim. Wilhelm Stein 1521 Pfarrverweser Volkach. ${ }^{142}$

Johann Steinmetz Kleriker Würzburger Diözese 1450 Mai einfache Dispens solutus et soluta (Reg. Pen. 4 39r - DN-Antragsnr. 34776). Johann Steinmetz, Kanoniker im Stift Haug zu Würzburg, 1439 dem Basler Konzil inkorporiert. ${ }^{143}$

Michael Stephani Kleriker Würzburger Diözese anwesend an der römischen Kurie 1507 April einfache Dispens presbiter et solutus, während zuvor Defekt verschwiegen (Reg. Pen. $53720 \mathrm{v}$ - DN-Antragsnr. 26665). Michael Stephani päpstlicher Familiar 1479 Provision auf Würzburger Pfründe, 1486 Pfarrei Nassau Diözese Würzburg und Priesterweihe in Rom. ${ }^{144}$

Weigand Stolz Würzburger Diözese 1451 März erste Dispens presbiter et soluta (Reg. Pen. $451 \mathrm{v}-\mathrm{DN}$ Antragsnr. 35792); in Rom 1451 März 20 erste Tonsur und Akolyth, 1451 April 10 Subdiakon, Kaplan am Katharinenaltar in Pfarrkirche Rörtingen (Rethin) Diözese Würzburg. ${ }^{145}$

139 August Amrhein, Die Würzburger Zivilgerichte erster Instanz, in: Arch. des HV von Unterfranken 56 (1914) 126.

140 Wendehorst, Neumünster (wie Anm. 14), 531; RG 6 251, Nr. 2414.

141 Wilhelm Oettinger, Ebrach und Erlenbach bei Neckarsulm, in: Würzburger Diözesangeschichtsbll. 34 (1972) 64; Engeh. Urkundenregesten (wie Anm. 51), 237 Nr. 309; Merzbacher, Allendorf (wie Anm. 80), 26.

142 Engel, Quellen (wie Anm. 3), 241 Nr. 1565, 247 Nr. 1610, 248 Nr. 1622, 262 Nr. 1724, 263 Nr. 1729; 1485 Mai 9: ASV S 846 132v-133r; 1485 Oktober 19: S 851 257rv; 1486 April 9: S 857 122v; 1487 Februar 8: S 866 84rv; 1487 Mai 13: $S 870$ 175v-176r; 1487 September 31: S 877 218v; 1488 Februar 16: S 885 56v; 1489 September 28: S 909 187v; nicht bei Wendehorst, Neumünster (wie Anm. 14), 169; Gerhard Egert, Eugen Schön. Stadtpfarrer von Volkach 1770-1842, in: MainfrJb 35 (1983) 112 Anm. 44.

143 Freudenberger, Papstschisma, in: Würzburger Diözesangeschichtsbll. 50 (1988) 85 Anm. 17.

144 Engeh Quellen (wie Anm. 3), 246 Nr. 1600; 259 Nr. 1701; 1486 Februar 14: ASV S 854266 r.

145 RG 6 592, Nr. 5792; Bendeh, Diözesanmatrikel (wie Anm. 14), 20 Nr. 877. 
Die Brüder Johann, Daniel und Philipp, Söhne des Johann Swopp von verschiedenen Müttern, Scholaren Würzburger Diözese 1479 Juli erste Dispens solutus et coniugata, bei Philipp presbiter et soluta (Reg. Pen. 28 206r - DN-Antragsnr. 13913-15). Peter Swapp aus Bischofsheim 1400 Studium Heidelberg, Vikar in Kitzingen. ${ }^{146}$

Michael Walteri Scholar Würzburger Diözese 1498 Dezember erste Dispens presbiter et soluta (Reg. Pen. 47 567s - DN-Antragsnr. 23546). Michael Waltheri alias Schimmelpfennig gestorben 148. März 22 Kanoniker im Stift Haug zu Würzburg [tot 1484 Dezember 30]. ${ }^{147}$

Georg Wernitzer Scholar Eichstätter Diözese 1521 Mai erste Dispens clericus et soluta (Reg. Pen. 67 12v DN-Antragsnr. 31168). Johann Wernitzer aus Rothenburg 1454 Studium Leipzig, bis 1466 Stiftskanoniker St. Gumprecht Ansbach, 1479 Kaplan am Marienaltar im Spital zu Rothenburg bis zum Tod 1503. ${ }^{148}$ Georg Wernt (Wernd) von Batzhausen Scholar Eichstätter Diözese 1488 Juni erste Dispens presbiter et soluta (Reg. Pen. 37 232r - DN-Antragsnr. 18680); 1488 September 23 durch Pfalzgraf bei Rhein präsentiert auf Katharinenfrühmesse Alfalter, 1494 Vikar [Kirch-?] Röttenbach [Präsentation Pfarrer Neunkirchen am Sand], 1495 Pfarrer Kirchensittenbach [Verleihung durch Bischof von Bamberg], 1504 Pfarrverweser Lauf an der Pegnitz, gestorben 1512 vor August 20. ${ }^{149}$

Georg Wydmann Scholar Würzburger Diözese 1498 Februar erste Dispens presbiter et coniugata (Reg. Pen. 46 423r - DN-Antragsnr. 23079). Georg Widmann der Ältere 1472 Notar, seit 1478 Pfarrer Tüngental, sein Sohn Georg der Jüngere geboren Tüngental 1486, Studium Heidelberg, seit 1518 Pfarrer Erlach und Gelbingen, Reformator und Chronist von Schwäbisch Hall, gestorben daselbst $1560 .{ }^{150}$ Nicht zu verwechseln Georg Widman, Summissar im Dom zu Bamberg, gestorben 1557 Oktober 12..$^{151}$

Johann Wilhelmi Scholar Würzburger Diözese 1458 Januar einfache Dispens presbiter et soluta (Reg. Pen. 6 120v - DN-Antragsnr. 1337). Johann Wilhelmi Kleriker Mainzer Diözese, 1428 Pfarrer Flörsbach mit Dispens presbiter et soluta. Johann Wilhelmi 1440-1443 Vikar im Stift Haug zu Würzburg. ${ }^{152}$

Peter Winter Scholar Würzburger Diözese 1458 Mai einfache Dispens presbiter et soluta (Reg. Pen. $6128 \mathrm{r}$ DN-Antragsnr. 1470); [identisch?] 1488 Pfarrvikar Heilbronn, Benediktiner aus Buchen, Abr in Amorbach 1503 bis Tod 1517 Juli 21, theologischer Schriftsteller und Freund des Trithemius. ${ }^{153}$ Jobst, Sohn des Peter Winter aus Obernbreit, 1476-1484 Pfarrer Niedernbreit. Paul Winter (Womter) Würzburger Diözese Scholar 1475 Dezember erste, Kleriker 1485 April erste Dispens presbiter et soluta, während zuvor Defekr verschwiegen (Reg. Pen. 24 209v, 34 270r - DN-Antragsnr. 12404, 16628). Johann Winter Scholar Würzburger Diözese 1488 März erste Dispens presbiter et soluta (Reg. Pen. 37 315r - DN-Antragsnr. 18424);

146 Ebner, Bruderschaftswesen (wie Anm. 29), 176, 252, 292, 340.

1471484 Dezember 30: S 843 183v; Engeh, Quellen (wie Anm. 3), 269 Nr. 1769; Ullrich, Liber regulae (wie Anm. 45), 268.

i48 Borchardt, Rothenburg (wie Anm. 22), 589 Nr. 346; Engel, Quellen (wie Anm. 3), 201 Nr. 1289.

149 Kist, Matrikel (wie Anm. 8), 430 Nr. 6557; von Guttenberg, Wendehorst, Bamberg (wie Anm. 13), 313 , 317,312 .

150 Engel, Quellen (wie Anm. 3), 241 Nr. 1567; Merzbacher, Allendorf (wie Anm. 80), 24; Ludwig Schnurrer, Die Wallfahrt zur Reinen Maria in Rothenburg, in: Würzburger Diözesangeschichtsbll. 42 (1980) 465f., 470, 497f.; Walter M. Brod, Würzburger Stadtansichten in Handschriften der Widman'schen Chronik der Stadt Schwäbisch Hall, in: MainfrJb 2 (1950) 343-349.

151 Wachter, Schematismus (wie Anm. 8), 546 Nr. 11038.

152 RG 4 Sp. 2515; Freudenberger, Papstschisma, in: Würzburger Diözesangeschichtsbll. 50 (1988) 92, 94.

153 Merzbacher, Allendorf (wie Anm. 80), 31; Arnold. Trithemius (wie Anm. 34), 159, 275; Werner Eichhorn, Das Nekrologium der Abtei Amorbach (767-1838), in: Würzburger Diözesangeschichtsbll. 31 (1969) 182. 
Priester 1491 Erste Bitten König Maximilians auf Zisterzienserinnenkloster Gnadental Diözese Würzburg. Johann Winther 1445 Doktor, Kanoniker und Scholaster von Neumünster [Vorgänger des Johann Vogel und Georg Hoeloch] zu Würzburg. ${ }^{154}$

Jakob Wirsberger (Wirsperger) Scholar Bamberger Diözese anwesend an der römischen Kurie 1504 einfache Dispens solutus et soluta (Reg. Pen. 52 644v - DN-Antragsnr. 26295).

Nikolaus Wirsing Scholar Würzburger Diözese anwesend an der römischen Kurie 1494 Februar erste Dispens presbiter et coniugata (Reg. Pen. 43 395r - DN-Antragsnr. 21672). Michael Wirsing 1479 Pfarrer Blaufelden. Johann Wirsing Dominikaner, 1492 Prior, 1502-1506 Lektor Würzburg. ${ }^{155}$

Oswald Wurm von Ingolstadt Scholar Eichstätter Diözese 1491 November erste Dispens solutus et soluta (Reg. Pen. 41 328v - DN-Antragsnr. 20506). Matthias Wurm Erste Bitten König Maximilians 1486 auf Stadt oder Dominikanerinnenkloster Rothenburg und 1489 auf Stift St. Marien und Gangolf in Teuerstadt außerhalb Bamberg. Margarethe Wurm Dominikanerin in Rothenburg 1494-1540. Jodokus Wurm Bürger 2u Rothenburg 1511. ${ }^{156}$

Johann Zeyner von Binswangen Scholar Würzburger Diözese 1517 November erste Dispens solutus et soluta mit Kommission an den Propst von St. Mauritius zu Speyer (Reg. Pen. 61 405r - DN-Antragsnr. 30170). Johann Zeiner 1527 Pfarrer Walkersbrunn [Gräbern, Präsentation durch die Familie Haller von Nürnberg], Lutheraner, 1550 gestorben. ${ }^{157}$

Johann Zeringer Scholar Bamberger Diözese 1479 Juli erste Dispens solutus et soluta (Reg. Pen. $28205 \mathrm{v}-$ DN-Antragsnr. 13902).

Die Brüder Stephan und Johann Zobel (Zebel) Scholaren Bamberger Diözese 1492 Oktober erste Dispens presbiter et soluta (Reg. Pen. 42 258v - DN-Antragsnr. 21031, 21032); Stephan 1502 Vikar im Stift St. Gangolf in Theuerstadt vor Bamberg, Johann 1518-1525 Frühmesser Pegnitz [Diözese Bamberg, Präsentation Pfarrer Büchenbach]. Johann Zobel aus Auerbach 1502 Studium Leipzig, 1504 baccalaureus, 1508 Magister, 1510 Dezember 21 Akolyth in Merseburg. ${ }^{158}$

Georg Zockle Scholar Würzburger Diözese 1481 April erste Dispens acolytus et soluta (Reg. Pen. 30 130v DN-Antragsnr. 14686). Hermann Zockle (Zackle, Zogklein) Priester, 1468 Notar in Würzburg, 1474 Kaplan Heiliggrabkapelle Iphofen, Pfarrer Ipsheim, Domvikar Würzburg, Prozeß um Pfründe in Schwäbisch Hall, 1483-1487 bischöflicher Fiskal in Würzburg. ${ }^{159}$

154 Plochmann, Marktbreit (wie Anm. 29), 45; Weiß, Erste Bitten (wie Anm. 34), 112 Nr. 53; Wendehorst, Neumünster (wie Anm. 14), 379.

155 Engeh, Urkundenregesten (wie Anm. 51), 248; Lore Sprandel-Krafft, Über die Bibliothek der Würzburger Dominikaner am Ende des Mittelalters, in: Würzburger Diözesangeschichtsbll. 48 (1986) 366, 392f., 395, 402, 411, 421.

156 Borchardt, Rothenburg (wie Anm. 22), 547, 556, 631.

157 Kist, Matrikel (wie Anm. 8), 451 Nr. 6836; von Guttenberg, Wendehorst, Bamberg (wie Anm. 13), 321.

158 Kist, Matrikel (wie Anm. 8), 455 Nr. 6905; Wachter, Schematismus (wie Anm. 8), 565 Nr. 11452, 11455; Weiß, Weihekandidaten (wie Anm. 46), 174; von Guttenberg, Wendehorst, Bamberg (wie Anm. 13), 331.

159 Zumkeller, Augustinerklöster (wie Anm. 29), 301; Merzbacher, Allendorf (wie Anm. 80), 262, 266; Wendehorst, Marienkapelle (QFW [wie Anm. 3] 27, 1974) 196f., 206; Ebner, Bruderschaftswesen (wie Anm. 29), 52; Meinrad Sehi, Die Bettelorden in der Seelsorgsgeschichte der Stadt und des Bistums Würzburg bis zum Konzil von Trient (Forsch. zur fränkischen Kirchen- und Theologiegesch. 8, Würzburg 1981) 395, 397, 440; Freudenberger, Birklingen (wie Anm. 75), 107, 114, 125; Oskar Friedlein, Die Satzungen des Chorherrenstiftes Möckmühl (1484), in: Würzburger Diözesangeschichtsbll. $37 / 38$ (1975/76) 348. 
Johann Zollner (Zalner) Scholar Würzburger Diözese 1488 Juni erste Dispens presbiter et soluta (Reg. Pen. 37 319r - DN-Antragsnr. 18609); resignierte 1509 Pfarrei Eichfeld bei Gerolzhofen. Johann Zollner Kleriker Würzburger Diözese 1484 Dekanat mit Präbende St. Gangolf zu Mainz 4 Mark, Prozeß um Domkanonikat mit Präbende Würzburg, resignierte 1485 Propstei St. Moritz zu Mainz 12 Mark, 1486 päpstlicher Familiar aus ritterlichem Geschlecht Archidiakonat und Propstei St. Germanus und Mauritius zu Speyer 16 Mark, 1487 Domkanonikat mit Präbende zu Worms 9 Mark und zu Mainz 16 oder 10 Mark, 1488 aber nur eine Pfründe $18 \mathrm{fl}$ th in tatsächlichem Besitz und deshalb Neuprovision auf Propstei St. Moritz zu Mainz 6 Mark, 1489 nach Resignationadarauf 8 fl th Jahrespension, 1490 Domkanonikat mit Präbende zu Speyer und nach zehnjähriger Anwesenheit an der römischen Kurie Erlaubnis, diese unter Beibehaltung der Privilegien eines anwesenden Familiaren für ein Jahr zu verlassen. ${ }^{160}$

Sigismund Zweifel Priester Eichstätter Diözese 1465 September erweiterte Dispens presbiter et soluta, während zuvor auctoritate ordinaria dispensiert, besaß Altar St. Johannis in Pfarrkirche Neumarkt Diözese Eichstätt 3 Mark (Reg. Pen. $13300 v$ - DN-Antragsnr. 5731). ${ }^{161}$

Illegitimität hat geistliche Karrieren also beschränkt und erschwert, wenn auch nicht völlig verhindert. In den Domkapiteln zu Würzburg, Bamberg und Eichstätt sind während des 15. Jahrhunderts keine Illegitimen nachzuweisen, obwohl die Statuten sie nicht ausdrücklich ausschlossen; verlangt wurde aber adelige Abkunft von beiden Eltern. Als Domizellar nominieren durfte man in Würzburg, wie 1319 festgelegt wurde ${ }^{162}$, nur personam ecclesie secundum consuetudinem non inhabilem, videlicet ex neutro parente condicione servili depressam, sed ex utroque nobilem ita ut saltim imperii vel huius vel alterius bonoris ecclesie videlicet principatum habentis vel alicuius principis secularis ministerialis sit vel ab antiquo communiter habeatur, aliasque corporis defectu aut deformi macula non notetur. In Bamberg wurde entsprechend 1390 als alte Gewohnheit festgeschrieben und 1399 durch Bonifaz IX. bestätigt, daß der neue Domkanoniker de militari prosapia procreatus ex utroque parente sein sollte. ${ }^{163}$

Wie von den Domkapiteln, so wurden Illegitime auch von den Turnieren ausgeschlossen, welche die fränkische Ritterschaft seit der zweiten Hälfte des 15. Jahrhunderts veranstaltete. Die Ordnung, welche die Ritter im Benehmen mit Bischof und mitregierendem Domkapitel 1479 für ihr Turnier in Würzburg aufstellten, sah ausdrücklich vor, „alle beruehmt und offentlich eheprecher und die in der unehe sitzen," sowie alle, "die sich unehrlich beweiben außer dem adl und nit wol besserten“ und alle, „die nit in der ehe

160 Franz Joseph Bendel, Besprechung von August Amrhein, Geschichte des Pfarrdorfes Eßfeld im Ochsenfurter Gau 820-1929 (Würzburg 1929), in: Arch. des HV von Unterfranken 68 (1929) 562 [nicht Eßfeld]; DAW Ortsdokumentation. 1484 Oktober 13: ASV S 841 84r; 1484 November 26: S 842 130v131r; 1485 Juni 8: S 847 174rv; 1485 Dezember 3: S 853 62rv; 1486 März 10: S 855191 v; 1487 Mai 31: $S 871$ 287r; 1487 Juni G: S 876 100rv; 1487 Juli 11: S 873 290r; 1488 März 20: S 883 104rv; 1488 April 26: S 885 49v-50r; 1488 Mai 2: S 885 9r-10r, V 731 278v-281r; 1489 Dezember 5: S 913 162rv; 1490 Januar 8: $S 914187 \mathrm{r}$; 1490 Juni 25: $S 919129 \mathrm{rv}$.

161 Suttner, Schematismus (wie Anm. 12), 52: Inhaber 1477 Stephan Hofner, Präsentation durch die Bürger der Stadt.

162 1319 Juli 7: MB 39, 125-130 Nr. 59.

163 Johannes Kist, Das Bamberger Domkapitel von 1399 bis 1556. Ein Beitrag zur Geschichte seiner Verfassung, seines Wirkens und seiner Mirglieder (Hist.-diplomatische Forsch. 7, Weimar 1943) 38f. 
gebohren sindt" nicht zu der Veranstaltung zuzulassen. ${ }^{164}$ Entsprechend wurden um diese Zeit die Söhne des Freiherrn Michael von Schwarzenberg aus seiner Verbindung mit Ursula Frankengrüner, Bürgerin zu Kitzingen, bei einem Turnier in Ingolstadt zurückgewiesen.

Diese Mesalliance Michaels I. von Schwarzenberg verdient kurz nähere Betrachtung. Michael war der älteste Sohn jenes Erkinger von Seinsheim (†1437), der als Familiengrablege die Kartause Astheim bei Volkach stiftete, durch König Sigismund wegen seiner Verdienste 1429 in den Freiherrenstand erhoben wurde und von dem das später gräfliche und heure fürstliche Haus Schwarzenberg abstammt. Michael selbst war in erster Ehe mit Gertraud von Kronberg vermählt, die am 29. Mai 1438 starb und in Astheim begraben wurde. Mit ihr hatte er vier Kinder, Michael II. ( $\dagger 1499)$, Anna (†1458), Margarethe $(† 1459)$ und Sigismund (†1452). In den vierziger Jahren ließ sich Michael I. mit Ursula Frankengrüner ein, die zunächst noch mit einem Bürger von Kitzingen vermählt war, der jedoch bald starb. Daraufhin machte Michael Ursula förmlich zu seiner Gemahlin und versuchte, die sechs Kinder Wolfgang, Michael III., Ursula, Anna, Magdalena und Agatha, die er mit Ursula actu fornicario, spe tamen et intentione adinvicem matrimonium contrahendi gezeugt hatte, für adelig und erbberechtigt zu erklären. Michael II., dessen Stellung als Haupterbe somit gefährdet war, warf seinen Vater und Ursula deshalb in den Kerker und zwang sie, durch besiegelte Briefe auf ihr Vorhaben zu verzichten. Dies taten sie auch, wandten sich dann aber an Calixt III. mit der Bitte, die entsprechenden Urkunden als erzwungen für nichrig, die Ehe weiterhin für gültig und die Kinder für legitim zu erklären. Calixt beauftragte 1457 zunächst den Würzburger Bischof Johann von Grumbach, dann den Abt des Schottenklosters in Würzburg mit der Untersuchung ${ }^{165}$, ohne sich jedoch de premissis certam notitiam non habentes sachlich festzulegen.

Als päpstlicher Beauftragter entschied der Abt Mauritius des Schottenklosters in Würzburg in der Tat, wie Michael I. es wünschte. ${ }^{166}$ Nun machte Michael I. mit der wahrscheinlich zähneknirschenden Zustimmung auch Michaels II. ein Testament und, nachdem er die Herrschaft Stephansberg bei Kitzingen gekauft hatte, ein Kodizill, wodurch Wolfgang und Michael III. als Wappengenossen und Nachfolger in der Herrschaft Stephansberg anerkannt wurden; Michael II. erhielt nur den Stammsitz Schwarzenberg. Diese Verfügungen wurden summarisch, also ohne die Einzelheiten aufzuzählen, 1464 durch Pius II. bzw. per rationi congruit durch Paul II. anerkannt sowie im päpstlichen Auftrag ${ }^{167}$ durch den Propst von Neumünster in Würzburg - bis 1465 Johann Heßler, dann Ludwig von Weyhers ${ }^{168}$ - und den Dekan von St. Gumprecht in Ansbach Matthias von Gulpen, ein bedeutender Jurist ${ }^{169}$ - im einzelnen bestätigt. Obwohl auch Kaiser Friedrich III. seine Genehmigung gab, konnten sich Wolfgang und Michael III. in

164 Ludwig Albrecht Frhr. v. Gumppenberg, Nachrichten über die Turniere zu Würzburg und Bamberg in den Jahren 1479 und 1480, in: Arch. des HV von Unterfranken 19/2 (1867) 173.

1651457 April 23: ASV S 499 148rv; 1457 Juni 20: V 460 91v-92r.

166 Bestätigung durch Bischof Johann III. von Würzburg 1458 Juni 20: StAN Ansb. OAA Nr. 1317.

167 1464 Juli 4: ASV S 575 28v; 1464 September 16: L $608216 \mathrm{v}-217 \mathrm{r}$.

168 Wendehorst Neumünster (wie Anm. 14), 305-307.

169 Adolf Bayer, S. Gumberts Kloster und Stift in Ansbach (Veröffentlichungen der Ges. für fränkische Gesch. 9/6, Würzburg 1984) 181. 
Stephansberg nicht auf Dauer halten. Michael I. starb am 19. März 1469 und wurde in Astheim begraben. Seine Witwe Ursula verbrachte ihren Lebensabend noch in Stephansberg, starb am 10. November 1484 und wurde ebenfalls in Astheim begraben.

Dann okkupierte Michaels II. Sohn Sigismund der Jüngere ( $\$ 1529)$, gestützt auf ein kaiserliches Mandat und mit Waffenhilfe durch die Kurfürsten Albrecht von Brandenburg und Ernst von Sachsen Feste und Herrschaft Stephansberg als Zubehör seiner Erbherrschaft Schwarzenberg. Damit löste er einen sehr verwickelten Konflikt aus, in den auch die Reichspolitik hineinspielte, den hier nachzuzeichnen aber nicht der Ort ist. Die jetzt als Bastarde depossedierten Brüder Wolfgang und Michael III. wandten sich hilfesuchend 1485 an Herzog Georg den Reicken von Landshut - Wolfgang war dessen Pfleger zu Graisbach -, an Bischof Rudolf von Scherenberg und das Domkapitel zu Würzburg sowie 1487 nach dem Vorgang Sigismunds des Jüngeren an Papst Innozenz VIII. Daß sogar Friedrich III. 1490 sein früheres Mandat gegen sie rückgängig machte und Sigismund dem Jüngeren befahl, Stephansberg zu räumen, nützte ihnen jedoch nichts. ${ }^{170}$

Aufschlußreich ist insbesondere die Haltung Würzburgs: Die Einkünfte, die Wolfgang und Michael III. laut Testament und Kodizill unter anderem aus würzburgischen Lehen und Pfändern zustanden, bestritt man ihnen nicht, doch in Stephansberg wollte man sich nicht einmischen, und zwar mit der Begründung, daß keine Lehens- oder sonstigen Beziehungen zum Hochstift bestanden. Die Zurückhaltung war politisch motiviert, doch darüber hinaus spürt man deutlich Reserviertheit gegenüber den Söhnen aus unstandesgemäßer Verbindung, denen Würzburg den Aufstieg zu adeliger Herrschaft mißgönnte, obwohl sie durch Papst und Kaiser legitimiert waren. Während Bischof und Domkapitel an Wolfgang und Michael III. im Frühjahr 1485 hinhaltende Briefe schrieben, hatten die anderen Schwarzenberg - Michael II., seine Söhne Erkinger und Sigismund der Jüngere, sein Onkel Sigismund der Ältere und dessen Sohn Johann, der berühmte Jurist - schon am 12. Januar 1485 Schloß und Herrschaft Stephansberg dem Bistum zu Lehen aufgetragen. Als die streitenden schwarzenbergischen Erben sich schließlich genügend verschuldet hatten, kaufte Markgraf Friedrich IV. von Ansbach 1502 um $5000 \mathrm{fl}$ die Herrschaft von Sigismund dem Jüngeren, seinem Amtmann zu Kitzingen. ${ }^{171}$ Damit verstärkten die Zollern ihre Stellung am Main, was nun allerdings in Würzburg durchaus auf Mißtrauen stieß. Das frühere Desinteresse an Stephansberg wird so als vorgeschoben entlarvt.

Ähnlich wie gegenüber den Schwarzenberg verhielt sich Würzburg 1518, als der Niederadelige Peter von Weyhers bat, seine fünf Söhne Michael, Peter, Sebastian, Kaspar und Martin Stulfuß, die er mit der Magd Agnes Stulfuß gezeugt hatte, unter anderem mit Einkünften von würzburgischen Lehengütern ausstatten zu dürfen. Bischof Lorenz von

170 Korrespondenz zwischen Würzburg und Landshut 1485: StAW Miscellanea 1024; 1486 Februar 9: ASV S 854 203r; 1486 März 7: S 855 256v-257r; 1487 Januar 11: S 865 10v-12r; Linz 1490 [1491 wegen Nativitätsstil] Dezember 31: Kop. StAN Ansb. OAA Nr. 1317; Gustav A. Seyler, Geschichre der Heraldik, Siebmacher's Wappenbuch Bd. A (Nürnberg 1885/89. ND Neustadt/Aisch 1970) 448; Karl Fürst zu Schwarzenberg, Geschichte des reichsständischen Hauses Schwarzenberg (Veröffentlichungen der Ges. für fränkische Gesch. IX/16, Neustadt/Aisch 1963) 41-52, 56f.

171 StAW WU 1/21a, 1/21c, Urk. Libell 642; Historischer Atlas von Bayern, Teil Franken l/6: Kitzingen. Bearb. v. Heinrich Weber (München 1967) 57. 
Bibra hat das offenbar anstandslos genehmigt. ${ }^{172}$ Angemessene Versorgung illegitimer Kinder wurde demnach ebensowenig ausgeschlossen wie das persönliche Fortkommen illegitimer Geistlicher, vorausgesetzt, der Vater besaß genügend Einfluß oder der illegitime Sohn erwarb sich ausreichende Verdienste. Es gibt Hinweise, daß Illegitime es schwerer hatten als andere, Karriere zu machen. Grundsätzlich versagt wurde Illegitimen in Franken - anderswo mögen die Verhältnisse nicht so gewesen sein - anscheinend die Ebenbürtigkeit, der Aufstieg in den erblichen Adel mit Ausübung entsprechender Herrschaft und Aufnahme in die Domkapirel einschließlich Zugang zu Prälaruren. Wie das Beispiel des Michael von Schwarzenberg zeigt, war für solche Nachteile nicht so sehr die in diesem Fall bestrittene Illegitimität, sondern der Standesunterschied der Eltern maßgebend. Man darf das Rechtsinstitut der Illegitimität mithin nie vom sozialen Umfeld der betroffenen Eltern und Kinder lösen. 
